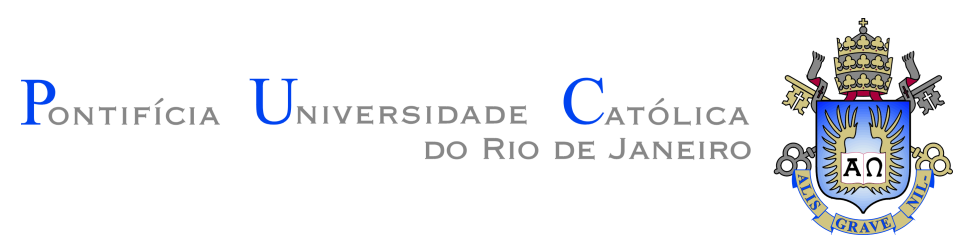

Arthur Bouchardet Cordeiro

\title{
Long-Term Drivers of Interest Rate Dynamics in Brazil
}

\section{Dissertação de Mestrado}

Thesis presented to the Programa de Pós-graduação em Economia, do Departamento de Economia da PUC-Rio in partial fulfillment of the requirements for the degree of Mestre em Economia.

Advisor : Prof. Carlos Viana de Carvalho

Co-advisor: $\quad$ Prof. Eduardo Zilberman 


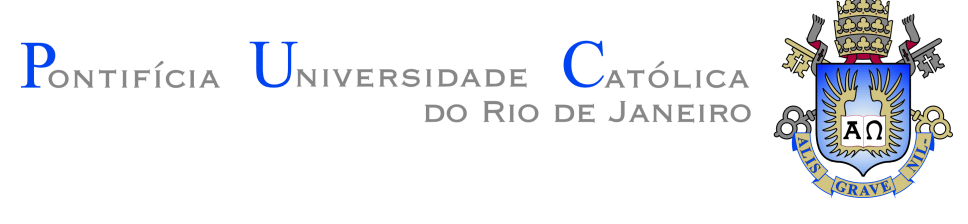

Arthur Bouchardet Cordeiro

Long-Term Drivers of Interest Rate Dynamics
in Brazil

Thesis presented to the Programa de Pós-graduação em Economia da PUC-Rio in partial fulfillment of the requirements for the degree of Mestre em Economia. Approved by the Examination Committee:

Prof. Carlos Viana de Carvalho Advisor

Departamento de Economia - PUC-Rio

Prof. Eduardo Zilberman

Co-advisor

Departamento de Economia - PUC-Rio

Prof. Yvan Becard

Departamento de Economia - PUC-Rio

Prof. Marco Bonomo

Departamento de Economia - INSPER

Rio de Janeiro, April the 12th, 2021 
All rights reserved.

\section{Arthur Bouchardet Cordeiro}

B.A. in Economics, Federal University of Minas Gerais.

Bibliographic data

Bouchardet Cordeiro, Arthur

Long-Term Drivers of Interest Rate Dynamics in Brazil / Arthur Bouchardet Cordeiro; advisor: Carlos Viana de CarvaIho; co-advisor: Eduardo Zilberman. - 2021.

52 f: il. color. ; $30 \mathrm{~cm}$

Dissertação (mestrado) - Pontifícia Universidade Católica do Rio de Janeiro, Departamento de Economia, 2021.

Inclui bibliografia

1. Economia - Teses. 2. Taxa de Juros Real. 3. Transição Demográfica. 4. Gastos do Governo. 5. Dívida Pública. 6. Secular Stagnation. 7. Previdência. 8. Política Monetária. I. Viana de Carvalho, Carlos. II. Zilberman, Eduardo. III. Pontifícia Universidade Católica do Rio de Janeiro. Departamento de Economia. IV. Título. 


\section{Acknowledgments}

I dedicate this work to my parents, who have always given me unconditional love and support. I thank my mom, Suzanne, for giving me comfort and confidence in stressful moments and finding the perfect balance between toughness and affection. I thank my dad, Sérgio, for teaching me how to pass through hard times with calm, respect and kindness, always giving me the best advice, even though I might take some time to notice it.

I am grateful to all my friends and family, who encouraged me to pursue my dreams and helped easing my mind from a tough routine of studies.

I also thank the faculty of PUC-Rio economics department, for building an incredible academic environment. I am specially indebted to my advisors, and now friends, prof. Carlos Viana de Carvalho and prof. Eduardo Zilberman, for teaching me uncountable lessons throughout this last year and always being available to give me advice.

Finally, I could not have succeeded in the master's without all the friends I made at PUC-Rio. They are the main reason why I will always remember those two years with care.

This study was financed in part by the Coordenação de Aperfeiçoamento de Pessoal de Nível Superior - Brasil (CAPES) - Finance Code 001 


\section{Abstract}

Bouchardet Cordeiro, Arthur; Viana de Carvalho, Carlos (Advisor); Zilberman, Eduardo (Co-Advisor). Long-Term Drivers of Interest Rate Dynamics in Brazil. Rio de Janeiro, 2021. 52p. Dissertação de Mestrado - Departamento de Economia, Pontifícia Universidade Católica do Rio de Janeiro.

I develop a life cycle model to evaluate the relative importance of several long-term drivers of real interest rates. The model is a generalization of Gertler (1999), including credit market imperfections and heterogeneity among workers to fully capture the effects of the demographic transition. I calibrate the model to the Brazilian economy, feeding it with profiles for government spending, public debt, productivity growth and demographic variables. The model explains $71 \%$ of the overall change in real interest rates in Brazil between 2000 and 2019. Demographic factors, especially increases in life expectancy, are the key drivers of the fall in real interest rates. These forces are partially compensated by increases in public debt and social security spending. Moreover, the framework suggests that real interest rates will keep falling over the next 20, reaching a level of $1.5 \%$ despite reasonable increases in government debt. However, possible effects of risk premia and global rates on domestic interest rates are absent from the analysis.

\section{Keywords}

Real Interest Rate; Demographic Transition; Government Spending; Public Debt; Secular Stagnation; Social Security; Monetary Polic. 


\section{Resumo}

Bouchardet Cordeiro, Arthur; Viana de Carvalho, Carlos; Zilberman, Eduardo. Determinantes de Longo Prazo da Taxa Real de Juros no Brasil. Rio de Janeiro, 2021. 52p. Dissertação de Mestrado - Departamento de Economia, Pontifícia Universidade Católica do Rio de Janeiro.

Eu desenvolvo um modelo de ciclo de vida para avaliar a importância relativa de vários determinantes de londo prazo da taxa de juros. O modelo é uma generalização de Gertler (1999), incluindo imperfeições no mercado de crédito e heterogeneidade entre trabalhadores para capturar totalmente os efeitos da transição demográfica. O modelo é calibrado para a economia brasileira, incluindo perfis para os gastos do governo, gastos com previdência, dívida pública, crescimento da produtividade e variáveis demográficas. O modelo explica $71 \%$ da variação total na taxa de juros brasileira entre 2000 e 2019. Fatores demográficos, especialmente aumentos na expectativa de vida, são os principais determinantes da queda nas taxas de juros reais. Essas forças são parcialmente compensadas por aumentos na dívida pública e nos gastos com previdência. Além disso, o arcabouço sugere que as taxas de juros reais continuarão caindo nos próximos 20 anos, atingindo o patamar de $1.5 \%$ a.a., apesar de aumentos razoáveis na dívida pública. No entanto, possíveis efeitos de prêmios de risco e juros globais nas taxas de juros domésticas não são incluídos na análise.

\section{Palavras-chave}

Taxa de Juros Real; Transição Demográfica; Gastos do Governo; Dívida Pública; Secular Stagnation; Previdência; Política Monetária. 


\section{Table of contents}

1 Introduction $\quad 11$

2 The Model $\quad 17$

$\begin{array}{ll}2.1 \text { Demographics, preferences and insurance } & 17\end{array}$

$\begin{array}{lll}2.2 \text { Households } & 19\end{array}$

$\begin{array}{lll}2.2 .1 & \text { Retirees } & 19\end{array}$

$\begin{array}{lll}2.2 .2 & \text { Mature Workers } & 20\end{array}$

2.2.3 Young Workers 22

2.2.3.1 Unconstrained Young Workers 22

2.2.3.2 Hand-to-Mouth Young Workers 23

2.3 Aggregation of households' decisions 24

2.4 Firms and Production 26

$\begin{array}{lll}2.5 & \text { Fiscal Policy } & 27\end{array}$

$\begin{array}{lll}2.6 & \text { Equilibrium } & 27\end{array}$

3 Calibration and Experiment $\quad 28$

4 Results $\quad 31$

4.1 Alternative Calibrations 34

4.2 The importance of credit constrained young workers 35

$\begin{array}{lll}4.3 & \text { Projections } & 36\end{array}$

$\begin{array}{lll}4.4 & \text { Structural Reform } & 37\end{array}$

$\begin{array}{lll}5 & \text { Conclusion } & 39\end{array}$

A Model Solution $\quad 42$

A.1 Retirees 42

A.2 Mature Workers 43

A.3 Young Workers 46

A.3.1 Consumption Savings Young Workers 46

B Effects of hand-to-mouth workers on MPC's 49

C Role of credit constrained young workers $\quad 51$ 


\section{List of figures}

Figure 1.1 Treasury bill interest rate at which short-term government securities are issued or traded in the market adjusted by inflation as measured by the GDP deflator.

Figure 1.2 yields on short-term government securities with maturity less than one year minus realized CPI inflation. The sample consists of Belgium, Germany, Denmark, Finland, France, Greece, Iceland, Ireland, Italy, Japan, Netherlands, Norway, Portugal, Spain, Sweden, United Kingdom, United States.

Figure 1.3 Left panel: Brazilian population growth rate in percentage points. Right panel: years of life expectancy at the time of birth in Brazil.

Figure 1.4 Top left panel: TFP growth in Brazil; Top right panel: government consumption in Brazil as a share of GDP; Bottom left panel: gross public debt in Brazil as a share of GDP; Bottom right panel: social security spending in Brazil as a share of GDP

Figure 3.1 Simulated and observed trajectories for population composition

Figure 4.1 Simulated and observed trajectories for real interest rates in Brazil between 2000 and 2019

Figure 4.2 Simulated and observed trajectories for the shares of consumption and investment to GDP

Figure 4.3 Changes in the equilibrium real interest rate as a result of policy, demographic and technological changes

Figure 4.4 Endogenous social security tax. Fixed consumption tax rate. 34

Figure $4.5 \quad \mu=0.05$.

Figure 4.6 Model without young workers and credit constraints 36

Figure 4.7 Projected debt to GDP ratio between 2021 and $2030 \quad 37$

Figure 4.8 Projected real interest rates between 2020 and $2040 \quad 38$

Figure C.1 Comparison between the benchmark model the framework with credit constrained young workers

Figure C.2 Population composition in the United States 


\section{List of tables}

Table 3.1 $\quad$ Parameter values 28

Table 3.2 Steady state exogenous variables 29 


\section{List of Abreviations}

IBGE - Instituto Brasileiro de Geografia e Estatística

IPEA - Instituto de Pesquisa Econômica Aplicada

BNDES - Banco Nacional de Desenvolvimento Econômico e Social

MPC - Marginal Propensity to Consume

OLG - Overlapping Generations 


\section{Introduction}

By the end of 2019, the Brazilian federal funds rate had reached a record low level of $4.5 \%$ per year, after the longest sequence of consecutive interest rate cuts in the country's history. Although short-term policy choices might have played a role in this process, a broader perspective poses a different interpretation. As Figure 1.1 shows, real interest rates have been falling in Brazil since the beginning of the century. This secular trend suggests that those rates are greatly affected by long-term forces and not only by business cycle events.

\section{$12,0 \%$}

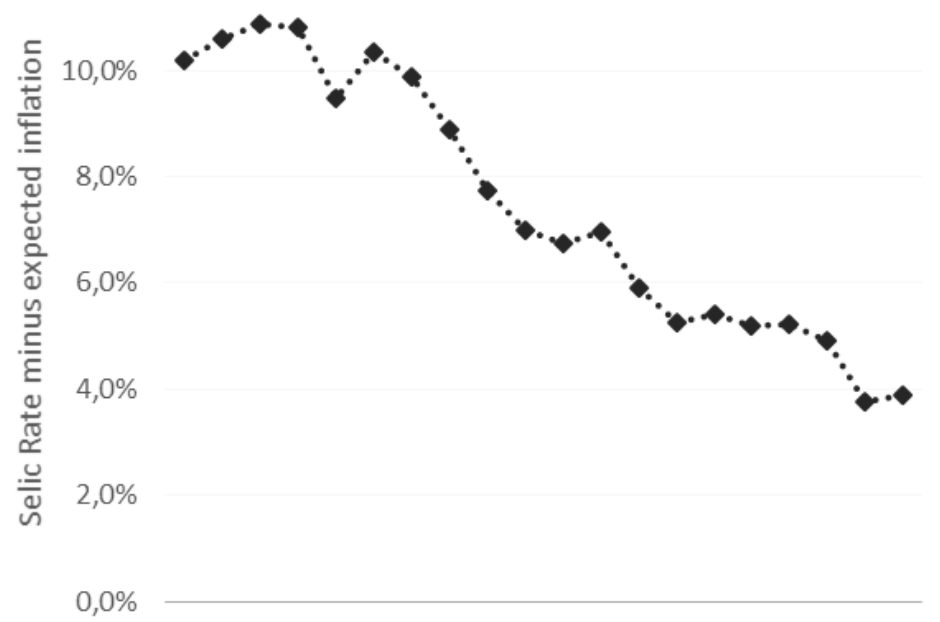

2000200220042006200820102012201420162018

Figure 1.1: Treasury bill interest rate at which short-term government securities are issued or traded in the market adjusted by inflation as measured by the GDP deflator.

This outlook is not exclusive to Brazil. As depicted in Figure 1.2, real interest rates have been falling in most advanced economies at least since the 1990's. This led researchers to speculate whether the current proximity of nominal rates to the zero lower bound in those economies is transitory, or if it is a "new normal". In this context, a flourishing literature started to look for possible long-term drivers of real interest rates, finding important candidates such as demography, productivity, government debt, government spending and social security systems ${ }^{1}$.

${ }^{1}$ For a great compilation of those studies see Summers and Rachel (2019) 


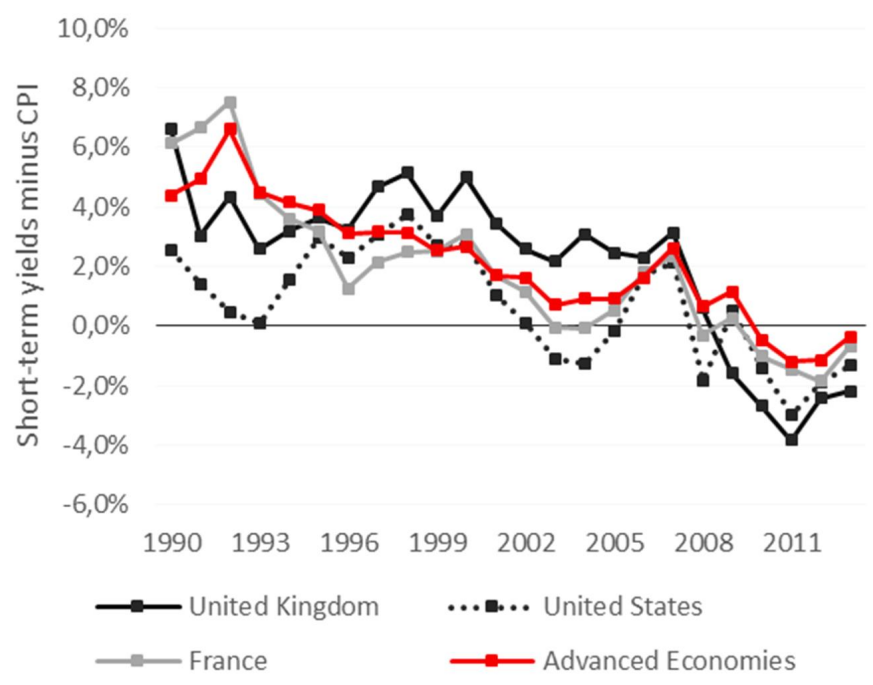

Figure 1.2: yields on short-term government securities with maturity less than one year minus realized CPI inflation. The sample consists of Belgium, Germany, Denmark, Finland, France, Greece, Iceland, Ireland, Italy, Japan, Netherlands, Norway, Portugal, Spain, Sweden, United Kingdom, United States.

The goal of this paper is to evaluate the relevance of each of those factors in the recent path of real interest rates in Brazil. I built a life-cycle model adapted to the Brazilian economy to clarify the channels through which demography, productivity growth, government consumption, social security and public debt may affect real interest rates. After simulating the model, I run several counterfactual analyses to shed light on the relative importance of those variables.

Probably the main driver of long-term movements in interest rates is demography ${ }^{2}$. Figure 1.3 shows that Brazil is passing through a fast demographic transition, with soaring life expectancy and decreasing population growth. This dynamics may induce changes in the structure of population and in individual behavior that affect real interest rates.

For a given age of retirement, increases in life expectancy encourage individuals to save more in order to maintain their consumption standards for a longer period of time after they stop working. Hence, higher values of life expectancy put downward pressure on real interest rates by increasing aggregate savings.

The standard literature identifies two possible effects of lower population growth. On the one hand, there is an increase in the capital-labor ratio, which causes a decline in the marginal product of capital, pushing down real interest rates. On the other hand, a decrease in the growth of population eventually

${ }^{2}$ Eggertsson et al. (2019) includes several of the above mentioned factors in his analysis of secular stagnation and finds that demography is the prevailing force acting on interest rates. Summers and Rachel (2019) find similar results. 

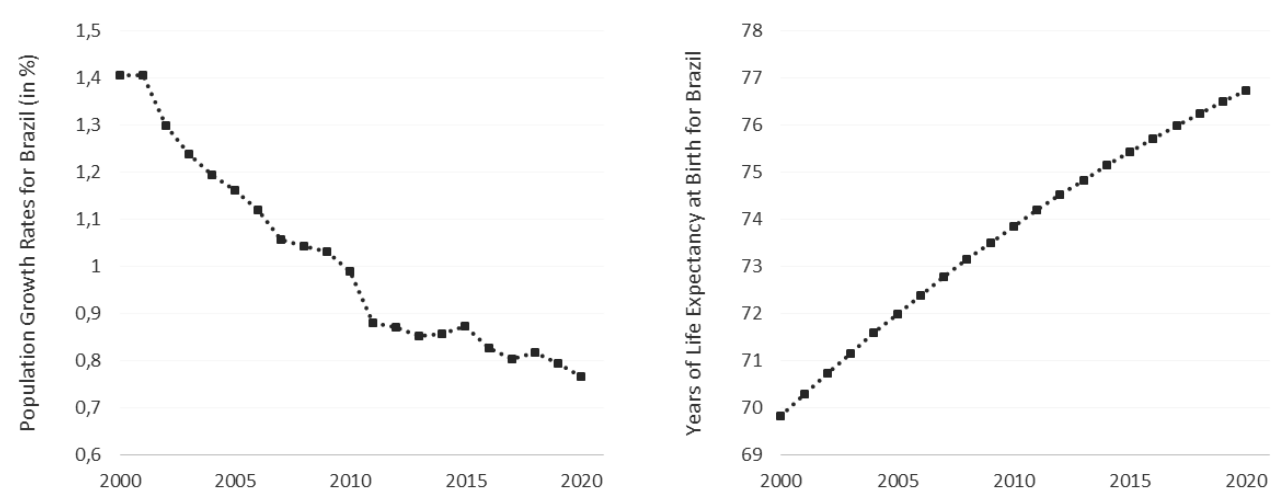

Figure 1.3: Left panel: Brazilian population growth rate in percentage points. Right panel: years of life expectancy at the time of birth in Brazil.

elevates the dependency ratio, i.e., the ratio between people 65 years old and older and people between 15 and 65 years old. Since retirees have a higher marginal propensity to consume, an upraised dependency ratio leads to lower savings per-capita, pulling real interests rates up.

However, the literature frequently overlooks the heterogeneity in the marginal propensity to consume among workers. Because of credit constraints in the beginning of their careers, young workers might save less than middle-age ones, consuming a higher share of their current income ${ }^{3}$. Therefore, a decrease in population growth may also push interest rates down by raising the ratio between mature and young workers, which would increase per capita savings among workers.

This "labor force composition channel" is essential for any analysis of the macroeconomic effects of demography, since it reinforces negative effects of lower population growth on real interest rates. However, this effect is absent from most studies on the subject. To my knowledge, the first paper to explicitly allow for this effect is Carrasco (2019), which builds a continuous time overlapping generations model with life-cycle wage profile for the U.S economy. He shows that the labor force composition channel is a key element to explain the hump-shaped path of interest rates in the U.S. since the 1960's ${ }^{4}$.

Another possible factor driving real interest rates down is the slowdown in productivity growth. With labor-augmenting technology, lower productivity diminishes the amount of effective labor, which raises the capital-labor ratio. Moreover, Eggertsson et al. (2019) argues that lower productivity negatively affects investment prospects, which also pushes interest rates down. As shown

\footnotetext{
${ }^{3}$ Recent studies highlight the existence of heterogeneity in the marginal propensity to consume caused by credit constraints. See Jappelli and Pistaferri (2014) and Fagereng et al. (2019).

${ }^{4}$ In Appendix B, I show that it is possible to obtain a similar result using the model of this paper, which is a much more tractable approach.
} 
in the first panel of Figure 1.4, the rate of growth of productivity in Brazil was very volatile in the last twenty years. However, one can clearly see that the first decade in the period was better than the second. In fact, productivity grew on average $1.88 \%$ per year between 2000 and 2010, slowing down to a year average of $0.33 \%$ growth between 2010 and 2019 .
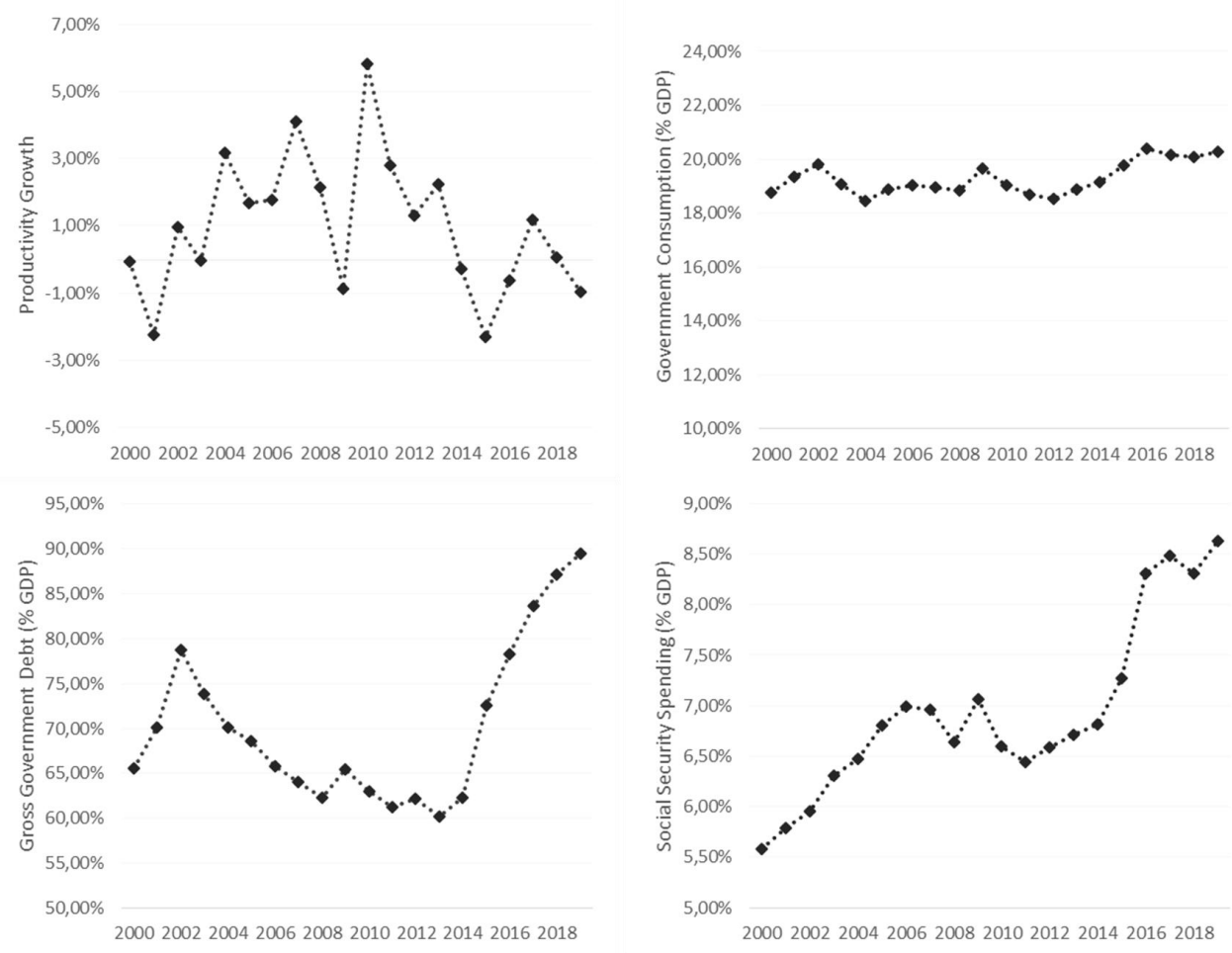

Figure 1.4: Top left panel: TFP growth in Brazil; Top right panel: government consumption in Brazil as a share of GDP; Bottom left panel: gross public debt in Brazil as a share of GDP; Bottom right panel: social security spending in Brazil as a share of GDP

There are also important factors that contribute to balance this downward trend in real interest rates. A large body of literature, summarized in Summers and Rachel (2019), highlights the influence of government policy on private behaviour, ultimately driving interest rates up. Government consumption and public debt, for example, may have positive impacts on real interest rates, by increasing the need for government financing. Similarly, increases in social security spending, may induce workers to save less during their life-cycle, as they expect to receive exogenous transfers from the government after retirement. The recent evolution of those government policy variables is presented in Figure 4.

Social security arrangements also play an important role in the interaction between demography and real interest rates. The minimal age of retirement, the total value of pension transfers and the returns on compulsory savings in fully-funded pension systems are all key factors in consumption-saving decisions through the life cycle, influencing aggregate savings and interest rates. 
In Brazil, the social security system is particularly interesting. It can be described as a combination of pay-as-you-go (PAYG) and fully funded pension systems. On the one hand, workers are taxed at a progressive rate and retire at a given minimum age. After retirement, they receive pensions proportional to their contributions. On the other hand, workers have a mandatory savings account called Time of Service Guarantee Fund (FGTS), which accumulates until retirement at below market rates. The government may use those compulsory savings to subsidize capital for firms via public investment banks ${ }^{5}$.

To evaluate the effects of different drivers of interest rates, I built a life-cycle model inspired by Gertler (1999), which is standard in the literature on macroeconomic effects of the demographic transition (Ferrero, 2010; Gourinchas and Rey, 2014; Carvalho et al., 2016; Summers and Rachel, 2019; Brito and Carvalho, 2015). The model includes three generations of households: young workers, mature workers and retirees. A given household will necessarily pass through all stages of life before he dies. In a similar fashion to Blanchard's (1985) perpetual youth framework, retirees have an exogenous probability of surviving each period, while young and mature workers have given probabilities of passing to the next generation. This life cycle structure induces heterogeneity in saving behaviour among households. Hence, the composition of population between young workers, mature workers and retirees becomes a key determinant of aggregate savings and real interest rates.

An important innovation of my model is the distinction between young and mature workers. While mature workers solve a standard consumptionsavings problem, young workers are credit constrained. To model this dynamics I assume that only a mass $\mu \in(0,1)$ of young workers is allowed to smooth consumption, while the remaining $1-\mu$ of of this group is hand-to-mouth, i.e., consume only their current income. This allows me to study how population growth affects real interest rates when young workers have a higher marginal propensity to consume, capturing all the aforementioned effects of the demographic transition on real interest rates.

I adapt the model to capture some peculiarities of the Brazilian economy. Particularly, there are two simultaneous social security arrangements at play. On the one hand, workers pay a constant share of their wages to the government in exchange for receiving exogenous transfers after retirement. On the other hand, they are subject to a compulsory savings system, managed by the government. Moreover, every household pays consumption taxes, while income taxes are paid only by workers. Finally, the government also acts in the

\footnotetext{
${ }^{5}$ Bonomo et al. (2016) build an OLG model to study the role of Brazilian social security arrangements in shaping the country's interest rates.
} 
production side of the economy, by subsidizing part of the capital used by firms. My modeling choices for these social security arrangements were largely based on Bonomo et al. (2016).

I feed the model with exogenous profiles for demographic variables, productivity growth, government consumption, social security spending and public debt, based on Brazilian data from 2000 to 2019. I compute a simulated path for the real interest rate and compare it to actual data to see if the model is able to explain the downward trend observed in the data. I also run several counterfactual analyses to evaluate how each one of the aforementioned variables would affect real interest rates if all the other variables remained constant.

There are three important caveats to my analysis. First, the model does not include any risk premium on the returns of sovereign bonds. Hence, increases in public debt only raises interest rates by being a burden in the government's budget constraint. This is a clear underestimation of the effects of public debt, specially when it reaches very high levels, since one would expect interest rates to go up to compensate investors for the higher risk of sovereign default. Second, the model is a closed economy and interest rates are determined only by domestic factors. However, in reality, domestic interest rates are affected by foreign interest rates, specially in small open economies like Brazil. In particular, it is quite possible that the recent fall in world's interest rates has posed a negative effect on Brazilian rates. Finally, I do not model inequality. By transferring resources to poorer agents, lower inequality tends to increase real interest rates, since MPCs are negatively correlated with wealth in the data.

The model captures nearly $71 \%$ of the change in Brazilian real interest rates between 2000 and 2019. Demographic variables play the major role in explaining the downward trend observed in the data, but the productivity slowdown is also an important factor pushing interest rates down. On the other hand, increases in social security spending and public debt are relevant forces that counterbalance this trend.

I also use model simulations to make projections. Interest rates will probably keep falling over the next 20 years, reaching a level of around $1.5 \%$. However, feasible economic reforms that increase productivity growth may offset this effect.

The remaining of the paper is divided into four sections. Section 2 presents the model, focusing on life-cycle heterogeneity among households. Section 3 describes the calibration and the experiments. Section 4 presents the results. Section 5 briefly concludes. 


\section{2}

\section{The Model}

There are three main types of agents in the economy: households, firms and the government. Households can be either young workers, mature workers or retirees. To simulate credit constraints, only a mass $\mu \in(0,1)$ of young workers is allowed to smooth consumption over time. The remaining $1-\mu$ of this group is assumed to be hand-to-mouth and consume only their current income. Besides paying income and consumption taxes, workers are forced to save a share of their income. This compulsory savings have below market returns payed by the government and can only be accessed after retirement.

Firms are perfectly competitive. They choose a mix of capital, young labor and mature labor to produce a homogeneous good, used for both consumption and investment. The government subsidizes production by supplying capital at below-market rental rates. Finally, the government takes spending as given and chooses a mix of taxes and one-period debt to satisfy its budget constraint.

\section{1}

\section{Demographics, preferences and insurance}

A household's life-cycle has three distinct stages: young worker $(y)$, mature worker $(w)$, and retiree $(r)$. At time $t-1$, young workers have mass $N_{t-1}^{y}$, mature workers have mass $N_{t-1}^{w}$ and retirees have mass $N_{t-1}^{r}$.

All households begin their lives as young workers. They stay young from period $t-1$ to period $t$ with probability $\theta_{t}$, or become mature workers with probability $1-\theta_{t}$. In period $t,\left(1+n-\theta_{t}\right) N_{t-1}^{y}$ new young workers are born. The law of motion for the mass of young workers is given by

$$
N_{t}^{y}=\theta_{t} N_{t-1}^{y}+\left(1+n_{t}-\theta_{t}\right) N_{t-1}^{y}=\left(1+n_{t}\right) N_{t-1}^{y} .
$$

Mature workers stay at the labor force from period $t-1$ to period $t$ with probability $\omega_{t}$ and retire with probability $1-\omega_{t}$. The mass of mature workers evolve according to

$$
N_{t}^{w}=\omega_{t} N_{t-1}^{w}+\left(1-\theta_{t}\right) N_{t-1}^{y} .
$$

Retirees survive from period $t-1$ to period $t$ with probability $\gamma_{t}$, which implies 
the following law of motion

$$
N_{t}^{r}=\gamma_{t} N_{t-1}^{r}+\left(1-\omega_{t}\right) N_{t-1}^{w} .
$$

From (2-1) and (2-2), I define the age composition of the labor force as $\psi_{t}^{y, w} \equiv N_{t}^{w} / N_{t}^{y}$, which evolves according to

$$
\left(1+n_{t}\right) \psi_{t}^{y, w}=\left(1-\theta_{t}\right)+\omega_{t} \psi_{t-1}^{y, w}
$$

At last, from (2-3) and (2-4) I define $\psi_{t}^{w, r} \equiv N_{t}^{r} / N_{t}^{w}$, which follows

$$
\psi_{t}^{w, r}=\frac{\left(1-\omega_{t}\right)+\gamma_{t} \psi_{t-1}^{w, r}}{\omega_{t}+\left(1-\theta_{t}\right) / \psi_{t}^{y, w}}
$$

Since there is uncertainty about the time of death, retirees may leave bequests after they past. To address the problem of what happens to those bequests, there is an annuities market, following Yaari (1965) and Blanchard (1985). At each period $t$, the insurance company pays an amount $Z_{t}$ to retirees in exchange for keeping their assets in case they die. Hence, its profits are given by

$$
\left(1-\gamma_{t}\right) R_{t-1} A_{t-t}^{r}-\gamma_{t} Z_{t}
$$

The zero profit condition implies that

$$
Z_{t}=\frac{\left(1-\gamma_{t}\right) R_{t-1} A_{t-t}^{r}}{\gamma_{t}}
$$

Therefore, total return on assets received by a retiree in period $t$ is given by

$$
R_{t-1} A_{t-1}^{r}+\frac{\left(1-\gamma_{t}\right) R_{t-1} A_{t-t}^{r}}{\gamma_{t}}=\frac{R_{t-1} A_{t-1}^{r}}{\gamma_{t}}
$$

Preferences for an individual of group $z \in\{y, w, r\}$ are given by a restricted version of the recursive non-expected utility family (Kreps and Porteus, 1978; Epstein and Zin, 1989) that assumes risk neutrality

$$
V_{t}^{z}=\left\{\left(C_{t}^{z}\right)^{\rho}+\beta^{z}\left[E_{t}\left(V_{t}^{x} \mid x=z\right)\right]^{\rho}\right\}^{\frac{1}{\rho}} .
$$

where $V_{t}^{z}$ and $C_{t}^{z}$ respectively stand for the value function and consumption of type $z$ agent at time $t$. Furthermore, different groups have different discount factors

$$
\beta^{z}= \begin{cases}\beta, & \text { if } z=y, w . \\ \gamma_{t+1} \beta, & \text { if } z=r\end{cases}
$$

The expected value of utility also differs across groups 


$$
E_{t}\left(V_{t}^{x} \mid x=z\right)= \begin{cases}\theta_{t+1} V_{t+1}^{y}+\left(1-\theta_{t+1}\right) V_{t+1}^{w}, & \text { if } z=y \\ \omega_{t+1} V_{t+1}^{w}+\left(1-\omega_{t+1}\right) V_{t+1}^{r}, & \text { if } z=w \\ V_{t+1}^{r}, & \text { if } z=r\end{cases}
$$

Epstein-Zin preferences allow for separability between the coefficient of relative risk aversion and the elasticity of intertemporal substitution. With standard risk averse preferences, the model would imply a strong precautionary saving motive for young agents, departing from actual saving/consumption choices. Risk-neutrality helps to prevent this behaviour. Freedom to calibrate the elasticity of intertemporal substitution $\left(\sigma \equiv(1-\rho)^{-1}\right)$ then enables reasonable responses of consumption and savings to changes in interest rates.

\section{2}

\section{Households}

At each period $t$, households choose how much to consume of the homogeneous good $C_{t}$ and allocate their wealth among investment in new physical capital $K_{t}$ and one-period government bonds $B_{t}$. The return on capital is equal to a real rate $R_{t}^{K}$ minus the depreciation rate, $\delta \in(0,1)$. Government bonds pay a gross return $R_{t}$.

\subsection{1}

\section{Retirees}

An individual who was born in period $i$, became a mature worker in period $j$ and retired in period $k$ will choose consumption $C_{t}^{r}(i, j, k)$ and assets $A_{t}^{r}(i, j, k)$, for $t \geq k$ to solve

$$
V_{t}^{r}(i, j, k)=\max \left\{\left(C_{t}^{r}(i, j, k)\right)^{\rho}+\gamma_{t+1} \beta\left[V_{t+1}^{r}(i, j, k)\right]^{\rho}\right\}^{\frac{1}{\rho}},
$$

subject to

$$
\left(1+\tau_{t}^{c}\right) C_{t}^{r}(i, j, k)+A_{t}^{r}(i, j, k)=\frac{R_{t-1} A_{t-1}^{r}(i, j, k)}{\gamma_{t}}+E_{t}^{r}
$$

where $E_{t}^{r}$ is an exogenous retirement benefit received from the government and $\tau_{t}^{c}$ is a tax on consumption. I define total assets $A_{t}^{r}(i, j, k) \equiv B_{t}^{r}(i, j, k)+$ $K_{t}^{r}(i, j, k)$, and equalize the returns on capital and bonds

$$
R_{t}=R_{t+1}^{K}+(1-\delta)
$$

Additionally, the optimization problem is subject to the consistency requirement 


$$
A_{t-1}^{r}(i, j, k)=A_{t-1}^{w}(i, j)+F_{t-1}^{w}(i, j),
$$

where $F_{t}^{w}$ is the total amount of assets accumulated through the compulsory savings program until period $t$.

Equation (2-9) shows that the assets accumulated through compulsory savings, that could not be used by the agent when he was part of the labor force, are incorporated to the amount of assets available for consumption after retirement. Appendix A.1 shows that consumption is a fraction of total wealth

$$
C_{t}^{r}(i, j, k)=\xi_{t}^{r}\left[\frac{R_{t-1} A_{t-1}^{r}(i, j, k)}{\gamma_{t}}+S_{t}^{r}\right],
$$

where $S_{t}^{r}$ stands for the present value of total social security benefits received by a retiree

$$
S_{t}^{r}=\sum_{v=0}^{\infty}\left\{\frac{E_{t+v}^{r}}{\prod_{s=0}^{v} \frac{R_{t-1+s}}{\gamma_{t+s}}}\right\}=E_{t}^{r}+\frac{\gamma_{t+1} S_{t+1}^{r}}{R_{t}}
$$

$\xi_{t}^{r}$ is the marginal propensity to consume out of wealth for a retiree and evolves according to the following first-order non-linear difference equation, derived in Appendix A.1

$$
\frac{1}{\xi_{t}^{r}}=\left(1+\tau_{t}^{c}\right)+\gamma_{t+1}\left(R_{t} T_{t+1}\right)^{\sigma-1} \beta^{\sigma} \frac{1}{\xi_{t+1}^{r}},
$$

where $T_{t+1} \equiv\left(1+\tau_{t}^{c}\right) /\left(1+\tau_{t+1}^{c}\right)$. Finally, Appendix A.1 also shows that the retiree's value function is linear in current consumption

$$
V_{t}^{r}(i, j, k)=\left[\xi_{t}^{r}\left(1+\tau_{t}^{c}\right)\right]^{-\frac{1}{\rho}} C_{t}^{r}(i, j, k)
$$

\subsection{2}

\section{Mature Workers}

An individual who was born in period $i$ and became a mature worker in period $j$ chooses consumption $C_{t}^{w}(i, j)$ and assets $A_{t}^{w}(i, j)$ to solve

$$
V_{t}^{w}(i, j)=\max \left\{\left(C_{t}^{w}(i, j)\right)^{\rho}+\beta\left[\omega_{t+1} V_{t+1}^{w}+\left(1-\omega_{t+1}\right) V_{t+1}^{r}\right]^{\rho}\right\}^{\frac{1}{\rho}},
$$

subject to

$$
\begin{gathered}
\left(1+\tau_{t}^{c}\right) C_{t}^{w}(i, j)+A_{t}^{w}(i, j)=R_{t-1} A_{t-1}^{w}(i, j)+W_{t}^{w}\left[1-\tau_{t}\right] \\
F_{t}^{w}(i, j)=R_{t-1}^{f} F_{t-1}^{w}(i, j)+\tau_{t}^{f} W_{t}^{w}
\end{gathered}
$$

where $R_{t}^{f}$ is the gross return on compulsory savings payed by the government, $W_{t}^{w}$ is the wage received by mature workers and $\tau_{t} \equiv \tau_{t}^{w}+\tau_{t}^{s s}+\tau_{t}^{f}$ is the sum of all income deductions (respectively, income tax, social security tax and 
mandatory savings). Again, there is a consistency requirement that

$$
\begin{aligned}
& A_{t-1}^{w}(i, t)=A_{t-1}^{y}(i), \\
& F_{t-1}^{w}(i, t)=F_{t-1}^{y}(i),
\end{aligned}
$$

where $F_{t}^{y}(i)$ is the amount of assets accumulated through compulsory savings while the worker was young ${ }^{1}$. Appendix A.2 shows that mature workers consumption is a fraction of total wealth

$$
C_{t}^{w}(i, j)=\xi_{t}^{w}\left[A_{t-1}^{w}(i, j) R_{t-1}+H_{t}^{w}+S_{t}^{w}+\mathcal{F}_{t}^{w}\right],
$$

where $H_{t}^{w}$ represents the present discounted value of current and future real wages net of income taxes for a mature worker

$$
H_{t}^{w}=\sum_{v=0}^{\infty}\left\{\frac{W_{t+v}^{w}\left(1-\tau_{t}\right)}{\prod_{s=0}^{v} \frac{R_{t-1+v} \Omega_{t+v}}{\omega_{t+s}}}\right\}=W_{t}^{w}\left(1-\tau_{t}\right)+\frac{\omega_{t+1} H_{t+1}^{w}}{R_{t} \Omega_{t+1}} .
$$

$S_{t}^{w}$ is the present discounted value of social security benefits for a mature worker after retirement

$$
S_{t}^{w}=\sum_{v=0}^{\infty}\left\{\frac{\frac{\left(\Omega_{t+v+1}-\omega_{t+v+1}\right) S_{t+v+1}^{w}}{\Omega_{t+v+1} R_{t+v}}}{\prod_{s=0}^{v} \Omega_{t+s} R_{t-1+s}}\right\}=\frac{\left(\Omega_{t+1}-\omega_{t+1}\right) S_{t+1}^{w}}{\Omega_{t+1} R_{t}}+\frac{\omega_{t+1} S_{t+1}^{w}}{\Omega_{t+1} R_{t}} .
$$

$\mathcal{F}_{t}^{w}$ is the present discounted value of the FGTS benefits received after retirement for a mature worker

$$
\mathcal{F}_{t}^{w}=\frac{\omega_{t+1} \mathcal{F}_{t+1}^{w}}{R_{t} \Omega_{t+1}}+\frac{\Omega_{t+1}-\omega_{t+1} F_{t}^{w}}{R_{t} \Omega_{t+1}} .
$$

Appendix A.2 also shows that workers' marginal propensity to consume follows the following difference equation

$$
\frac{1}{\xi_{t}^{w}}=\left(1+\tau_{t}^{c}\right)+\left[\Omega_{t+1} T_{t+1} R_{t}\right]^{\sigma-1} \beta^{\sigma} \frac{1}{\xi_{t}^{w}} .
$$

The adjustment term $\Omega_{t}$ that appears in equations (12), (13), (14) and (15) depends on the ratio between the marginal propensities to consume of retirees and mature workers and is defined as

$$
\Omega_{t} \equiv \omega_{t}+\left(1-\omega_{t}\right)\left(\frac{\xi_{t}^{r}}{\xi_{t}^{w}}\right)^{\frac{1}{1-\sigma}}
$$

Finally, as for retirees, mature workers value function is linear in current consumption

$$
V_{t}^{w}(i, j)=\left[\left(1+\tau_{t}^{c}\right)\left(\Delta_{t}^{w}\right)^{\rho}\right]^{-1} C_{t}^{w}(i, j)
$$

${ }^{1}$ As I will show later in the text, young workers can be either credit-constrained or unconstrained. The superscript $y$ is used to describe young workers in general. Creditconstrained young workers are denoted by the superscript $h$ (which stands for "hand-tomouth), while unconstrained young workers are denoted by cs (consumption-savings). 


\subsection{3}

\section{Young Workers}

To simulate the effect o credit constraints, only a mass $\mu \in(0,1)$ of young workers is allowed to smooth consumption over time and have access to capital and financial markets. The remaining $1-\mu$ is assumed to be hand-to-mouth and consume only their current income.

The bottom line of this assumption is that the aggregate marginal propensity to consume of young workers will be higher than the MPC of mature workers, bringing the model close to actual data. This would never happen if every young worker were allowed to smooth consumption. Knowing that they will necessarily reach middle-age and retire before they die, unrestricted young workers save a greater share of their assets than mature workers.

\subsubsection{1}

\section{Unconstrained Young Workers}

A young worker who does not face credit constraints will choose consumption $C_{t}^{c s}(i)$ and assets $A_{t}^{c s}(i)$ to solve

$$
V_{t}^{c s}(i)=\max \left\{\left(C_{t}^{c s}(i)\right)^{\rho}+\beta\left[\theta_{t+1} V_{t+1}^{c s}+\left(1-\theta_{t+1}\right) V_{t+1}^{w}\right]^{\rho}\right\}^{\frac{1}{\rho}}
$$

subject to,

$$
\begin{gathered}
\left(1+\tau_{t}^{c}\right) C_{t}^{c s}(i)+A_{t}^{c s}(i)=R_{t-1} A_{t-1}^{c s}(i)+W_{t}^{y}\left[1-\tau_{t}\right] \\
F_{t}^{c s}(i)=R_{t-1}^{f} F_{t-1}^{c s}(i)+\tau_{t}^{f} W_{t}^{y}
\end{gathered}
$$

The superscript $c s$ stands for "consumption-savings", meaning that they are allowed to save and smooth consumption. As in previous cases, appendix A.3 shows that consumption is a fraction of total wealth for consumption-savings young workers

$$
C_{t}^{c s}(i)=\xi_{t}^{c s}\left[A_{t-1}^{c s}(i) R_{t-1}+H_{t}^{c s}+S_{t}^{c s}+\mathcal{F}_{t}^{c s}\right]
$$

where $H_{t}^{c s}$ represents the present discounted value of current and future real wages net of income and lump-some taxation for a young worker

$$
H_{t}^{c s}=W_{t}^{c s}\left(1-\tau_{t}\right)+\frac{\theta_{t+1} H_{t+1}^{c s}+\left[\frac{\xi_{t+1}^{w}}{\xi_{t}^{c s}}\right]^{\frac{1}{1-\sigma}}\left(1-\theta_{t+1}\right) H_{t+1}^{w}}{\Theta_{t+1} R_{t}} .
$$

$S_{t}^{c s}$ is the present discounted value of social security benefits for a young worker after retirement 


$$
S_{t}^{c s}=\frac{\left(\Theta_{t+1}-\theta_{t+1}\right) S_{t+1}^{w}}{\Theta_{t+1} R_{t}}+\frac{\theta_{t+1} S_{t+1}^{c s}}{\Theta_{t+1} R_{t}}
$$

$\mathcal{F}_{t}^{c s}$ is the present discounted value of the FGTS benefits received after retirement for a young worker

$$
\mathcal{F}_{t}^{c s}=\frac{\left(\Theta_{t+1}-\theta_{t+1}\right) \mathcal{F}_{t+1}^{w}}{\Theta_{t+1} R_{t}}+\frac{\theta_{t+1} \mathcal{F}_{t+1}^{c s}}{\Theta_{t+1} R_{t}} .
$$

where the adjustment term $\Theta_{t}$ is defined as

$$
\Theta_{t} \equiv \theta_{t}+\left(1-\theta_{t}\right)\left(\frac{\xi_{t}^{w}}{\xi_{t}^{c s}}\right)^{\frac{1}{1-\sigma}}
$$

The first-order non-linear equation for the marginal propensity to consume is given by

$$
\frac{1}{\xi_{t}^{c s}}=\left(1+\tau_{t}^{c}\right)+\left[\Theta_{t+1} T_{t+1} R_{t}\right]^{\sigma-1} \beta^{\sigma} \frac{1}{\xi_{t+1}^{c s}} .
$$

Lastly, the value function of consumption-savings young workers is linear in consumption

$$
V_{t}^{c s}(i)=\left[\left(1+\tau_{t}^{c}\right)\left(\Delta_{t}^{c s}\right)^{\rho}\right]^{-1} C_{t}^{c s}(i)
$$

\subsubsection{2}

\section{Hand-to-Mouth Young Workers}

A hand-to-mouth young worker cannot smooth consumption through the life cycle. Hence, his consumption in period $t$ is equal to current available income

$$
\left(1+\tau_{t}^{c}\right) C_{t}^{h}(i)=W_{t}^{y}\left(1-\tau_{t}\right) .
$$

where $\tau_{t} \equiv \tau_{t}^{w}+\tau_{t}^{s s}+\tau_{t}^{f}$. The only way that hand-to-mouth young workers accumulate assets is via compulsory savings that can only be used after retirement

$$
F_{t}^{h}(i)=R_{t-1}^{f} F_{t-1}^{h}(i)+\tau_{t}^{f} W_{t}^{y} .
$$

Just like unconstrained young workers, hand-to-mouth young workers will eventually become mature. This dynamic is clear in the consistency requirements (2-14) and (2-15), where the superscript $y$ can be replaced by $c s$ or $h$ depending on whether the newly aged mature worker used to be unconstrained or credit-constrained. Of course, if he used to be credit-constrained, $A_{t-1}^{y}(i)=A_{t-1}^{h}=0$, since hand-to-mouth young workers do not accumulate assets voluntarily.

In Appendix B, I show how this mass of hand-to-mouth young workers is essential for the model to generate aggregate marginal propensity to consume higher for young workers than for mature workers. 


\section{3}

\section{Aggregation of households' decisions}

Finding aggregate consumption relations is simple, since marginal propensities to consume for each age group are independent of individual characteristics. Aggregate consumption of retirees $\left(C_{t}^{r}\right)$ is given by

$$
C_{t}^{r}=\xi_{t}^{r}\left[A_{t-1}^{r} R_{t-1}+S_{t}\right]
$$

where $A_{t-1}^{z}$ is the total financial wealth that members of group $z \in\{y, w, r\}$ carry from period $t-1$ to period $t$. $S_{t}$ is the present value of social security benefits for retirees in the aggregate and evolves according to

$$
S_{t}=E_{t}+\frac{\gamma_{t+1} S_{t+1}}{\left(1+n_{t+1}\right) R_{t}} \frac{\psi_{t}^{w, r} \psi_{t}^{y, w}}{\psi_{t+1}^{w, r} \psi_{t+1}^{y, w}},
$$

where $S_{t} \equiv N_{t}^{r} S_{t}^{r}$ and $E_{t} \equiv N_{t}^{r} E_{t}^{r}$. Aggregate consumption by mature workers in period $t\left(C_{t}^{w}\right)$ is given by

$$
C_{t}^{w}=\xi_{t}^{w}\left[A_{t-1}^{w} R_{t-1}+\tilde{H}_{t}+\tilde{S}_{t}+\tilde{\mathcal{F}}_{t}\right],
$$

where $\tilde{H}_{t}$ is the aggregate value of mature workers' human wealth and evolves through

$$
\tilde{H}_{t} \equiv N_{t}^{w} H_{t}^{w}=N_{t}^{w}\left[W_{t}^{w}\left(1-\tau_{t}\right)\right]+\frac{\omega_{t+1} \tilde{H}_{t+1}}{\Omega_{t+1} R_{t}\left(1+n_{t+1}\right)} \frac{\psi_{t}^{y, w}}{\psi_{t+1}^{y, w}} .
$$

$\tilde{S}_{t}$ is the aggregate present discounted value of social security services received by mature workers after retirement and is such that

$$
\tilde{S}_{t} \equiv N_{t}^{w} S_{t}^{w}=\left\{\frac{\omega_{t+1} \tilde{S}_{t+1}}{\Omega_{t+1} R_{t}}+\frac{\left[\Omega_{t+1}-\omega_{t+1}\right] S_{t+1}}{\Omega_{t+1} R_{t} \psi_{t+1}}\right\} \frac{\psi_{t}^{*}}{\psi_{t+1}^{*}\left(1+n_{t+1}\right)},
$$

and $\tilde{\mathcal{F}}_{t}$ is the aggregate of the present discounted value of FGTS benefits received after retirement for mature workers

$$
\tilde{\mathcal{F}}_{t} \equiv N_{t}^{w} \mathcal{F}_{t}^{w}=\left\{\frac{\omega_{t+1} \tilde{\mathcal{F}}_{t+1}}{\Omega_{t+1} R_{t}}+\frac{\left[\Omega_{t+1}-\omega_{t+1}\right] F_{t+1}^{w}}{\Omega_{t+1} R_{t} \psi_{t+1}^{w, r}}\right\} \frac{\psi_{t}^{y, w}}{\psi_{t+1}^{y, w}\left(1+n_{t+1}\right)} .
$$

Aggregate consumption by non-restricted young workers in period $t\left(C_{t}^{c s}\right)$ is

$$
C_{t}^{c s}=\xi_{t}^{c s}\left[A_{t-1}^{c s} R_{t-1}+\hat{H}_{t}+\hat{S}_{t}+\hat{\mathcal{F}}_{t}\right]
$$

where $\hat{H}_{t}$ is the aggregate value of mature workers' human wealth and evolves according to

$$
\begin{aligned}
\hat{H}_{t} \equiv \mu N_{t}^{y} H_{t}^{c s}=\mu N_{t}^{y}\left[W_{t}^{y}(1\right. & \left.\left.-\tau_{t}\right)\right]+\frac{\theta_{t+1} \hat{H}_{t+1}}{\Theta_{t+1} R_{t}\left(1+n_{t+1}\right)} \\
& +\frac{\left[\Theta_{t+1}-\theta_{t+1}\right] \tilde{H}_{t+1}}{\Theta_{t+1} R_{t}\left(1+n_{t+1}\right) \psi_{t+1}^{y, w}} .
\end{aligned}
$$


$\hat{S}_{t}$ is the aggregate present discounted value of social security services received by young workers after retirement and is such that

$$
\hat{S}_{t} \equiv \mu N_{t}^{y} S_{t}^{c s}=\frac{\theta_{t+1} \hat{S}_{t+1}}{\Theta_{t+1} R_{t}\left(1+n_{t+1}\right)}+\frac{\left[\Theta_{t+1}-\theta_{t+1}\right] \tilde{S}_{t+1}}{\Theta_{t+1} R_{t}\left(1+n_{t+1}\right) \psi_{t+1}^{y, w}},
$$

and $\hat{\mathcal{F}}_{t}$ is the aggregate of the present discounted value of FGTS benefits received after retirement for young workers

$$
\hat{\mathcal{F}}_{t} \equiv \mu N_{t}^{y} \mathcal{F}_{t}^{c s}=\frac{\theta_{t+1} \hat{\mathcal{F}}_{t+1}}{\Theta_{t+1} R_{t}\left(1+n_{t+1}\right)}+\frac{\left[\Theta_{t+1}-\theta_{t+1}\right] \tilde{\mathcal{F}}_{t+1}}{\Theta_{t+1} R_{t}\left(1+n_{t+1}\right) \psi_{t+1}^{y, w}} .
$$

For hand-to-mouth young workers, aggregate consumption $C_{t}^{h}$ is simply equal to the aggregate value of current income net of income deductions

$$
\left(1+\tau_{t}^{c}\right) C_{t}^{h}=(1-\mu) N_{t}^{y}\left[W_{t}^{y}\left(1-\tau_{t}\right)\right] .
$$

Finally, aggregate consumption $\left(C_{t}\right)$ is just the sum of retirees, mature workers and young workers consumption

$$
\begin{array}{r}
C_{t}=\frac{(1-\mu)}{\left(1+\tau_{t}^{c}\right)} N_{t}^{y}\left[W_{t}^{y}\left(1-\tau_{t}\right)\right]+\xi_{t}^{c s}\left[A_{t-1}^{c s} R_{t-1}+\hat{H}_{t}+\hat{S}_{t}+\hat{\mathcal{F}}_{t}\right] \\
\quad+\xi_{t}^{w}\left[A_{t-1}^{w} R_{t-1}+\tilde{H}_{t}+\tilde{S}_{t}+\tilde{\mathcal{F}}_{t}\right]+\xi_{t}^{r}\left[A_{t-1}^{r} R_{t-1}+S_{t}\right]
\end{array}
$$

An important element of the model is the evolution of asset holdings by agents and how it is integrated with compulsory savings. Every period, a number of mature workers retire, gaining access to the assets accumulated through compulsory savings. On aggregate, these assets, suddenly available for retirees on period $t$, depend on the evolution of total compulsory savings of mature workers and on the share of mature workers who retire from $t-1$ to $t$

$$
F_{t}^{r}=\left(1-\omega_{t}\right)\left(R_{t-1}^{f} F_{t-1}^{w}+\tau_{t}^{f} N_{t}^{w} W_{t}^{w}\right)
$$

Aggregate compulsory asset holdings of mature workers in period $t$ is equal to the mandatory savings of those workers who did not retire plus the assets forcibly accumulated by young workers who became mature.

$$
F_{t}^{w}=\omega_{t}\left(R_{t-1}^{f} F_{t-1}^{w}+\tau_{t}^{f} N_{t}^{w} W_{t}^{w}\right)+\left(1-\theta_{t}\right)\left(R_{t-1}^{f} F_{t-1}^{y}+\tau_{t}^{f} N_{t}^{y} W_{t}^{y}\right)
$$

Aggregate compulsory asset holdings of young workers is just the amount of assets accumulated thus far by young workers who remained young.

$$
F_{t}^{y}=\theta_{t}\left(R_{t-1}^{f} F_{t-1}^{y}+\tau_{t}^{f} N_{t}^{y} W_{t}^{y}\right)
$$

To conclude, I must describe the evolution of the assets available for agents to use for consumption. Total assets held by households is the sum of $A_{t}^{r}, A_{t}^{w}$ and $A_{t}^{y}$, where $A_{t}^{y}=A_{t}^{c s}$, because hand-to-mouth young workers only 
have compulsory savings. Aggregate assets in the hands of retirees in period $t$ are equal to the total amount of assets saved by those agents, plus the savings of the share of mature workers who retired from $t-1$ to $t$. Moreover, retirees also receive the assets accumulated through compulsory savings

$$
\begin{array}{r}
A_{t}^{r}=R_{t-1} A_{t-1}^{r}+E_{t}-\left(1+\tau_{t}^{c}\right) C_{t}^{r} \\
+\left(1-\omega_{t+1}\right)\left[R_{t-1} A_{t-1}^{w}+N_{t}^{w}\left(W_{t}^{w}\left(1-\tau_{t}\right)\right)-\left(1+\tau_{t}^{c}\right) C_{t}^{w}\right]+F_{t}^{r} .
\end{array}
$$

Aggregate assets in the hands of mature workers follow

$$
\begin{array}{r}
A_{t}^{w}=\omega_{t+1}\left[R_{t-1} A_{t-1}^{w}+N_{t}^{w}\left(W_{t}^{w}\right)-\left(1+\tau_{t}^{c}\right) C_{t}^{w}\right] \\
+\left(1-\theta_{t+1}\right)\left[R_{t-1} A_{t-1}^{c s}+\mu N_{t}^{y}\left(W_{t}^{y}\left(1-\tau_{t}\right)\right)-\left(1+\tau_{t}^{c}\right) C_{t}^{c s}\right] .
\end{array}
$$

Finally, aggregate assets held by young workers evolve according to

$$
A_{t}^{c s}=\theta_{t+1}\left[R_{t-1} A_{t-1}^{c s}+\mu N_{t}^{y}\left(W_{t}^{y}\left(1-\tau_{t}\right)\right)-\left(1+\tau_{t}^{c}\right) C_{t}^{y}\right] .
$$

\section{4}

\section{Firms and Production}

The production side of the model is standard. Competitive firms use capital and labor to produce a single homogeneous good according to the production function

$$
Y_{t}=\left(X_{t} N_{t}^{w}\right)^{\alpha}\left(X_{t} N_{t}^{y}\right)^{\eta} K_{t-1}^{1-\alpha-\eta}
$$

where $X_{t}$ is a labor augmenting technology factor and grows exogenously at rare $x_{t}$

$$
X_{t}=\left(1+x_{t}\right) X_{t-1}
$$

Government subsidizes capital, i.e. firms can rent capital from the government at a smaller rate $\bar{R}$. Hence, the firm maximizes

$$
Y_{t}-W_{t}^{w} N_{t}^{w}-W_{t}^{y} N_{t}^{y}-\phi R_{t}^{K} K_{t-1}-(1-\phi) \bar{R}_{t} K_{t-1},
$$

where $1-\phi$ is the share of subsidized capital. The first order conditions for young labor, mature labor and capital are expressed below

$$
\begin{gathered}
W_{t}^{w} N_{t}^{w}=\alpha Y_{t} \\
W_{t}^{y} N_{t}^{y}=\eta Y_{t} \\
{\left[\phi R_{t}^{K}+(1-\phi) \bar{R}_{t}\right] K_{t-1}=(1-\alpha-\eta) Y_{t} .}
\end{gathered}
$$




\section{5}

\section{Fiscal Policy}

The flow budget constraint of the government is given by

$$
\begin{array}{r}
G_{t}+E_{t}+R_{t-1} B_{t-1}+\left(R_{t-1}^{f}-1\right)\left(F_{t-1}^{w}+F_{t-1}^{y}\right) \\
=B_{t}+\tau_{c} C_{t}+\left(N_{t}^{w} W_{t}^{w}+N_{t}^{y} W_{t}^{y}\right) \tau+\bar{R}_{t}(1-\phi) K_{t-1} .
\end{array}
$$

The government finances spendings $G_{t}$, social security transfers $E_{t}$ and the remuneration of compulsory savings by issuing one-period debt $B_{t}$ and charging taxes. It uses part of the capital accumulated with compulsory savings to subsidize a share $(1-\phi)$ of the capital used in production. Moreover, it gets an extra revenue from the return on subsidized capital.

\section{6}

\section{Equilibrium}

The equilibrium is defined as a sequence of quantities $\left\{C_{t}^{r}, C_{t}^{w}, C_{t}^{c s}, C_{t}^{h m}, C_{t}, A_{t}^{r}, A_{t}^{w}, A_{t}^{c s}, A_{t}, S_{t}, \tilde{S}_{t}, \hat{S}_{t}, \tilde{H}_{t}, \hat{H}_{t}, \tilde{\mathcal{F}}_{t}, \hat{\mathcal{F}}_{t}, F_{t}^{w}, F_{t}^{c s}, K_{t}, Y_{t}\right.$, $\left.I_{t}, B_{t}, T_{t}, G_{t}, E_{t}, \psi_{t}^{y, w}, \psi_{t}^{w, r}\right\}$, a sequence of prices $\left\{R_{t}, R_{t}^{K}, R_{t}^{f}, \bar{R}_{t}, W_{t}^{w}, W_{t}^{y}\right\}$ and a sequence of marginal propensities to consume $\left\{\xi_{t}^{r}, \xi_{t}^{w}, \xi_{t}^{c s}, \Omega_{t}, \Theta_{t}\right\}$ such that

1. Households maximize utility subject to their budget constraints according to sections 2.2.1, 2.2.2 and 2.2.3.

2. Firms maximize profits according to section 2.4.

3. Government chooses the mix of taxes and debt to satisfy its budget constraint as in section 2.5.

4. All markets clear and the resource constraint $C_{t}+I_{t}+G_{t}=Y_{t}$ is met. In particular, $K_{t}=I_{t}+(1-\delta) K_{t-1}$.

I will study an equilibrium with constant probability of retirement $\left(\omega_{t}=\omega, \forall t\right)$ and constant probability of becoming a mature worker $\left(\theta_{t}=\theta, \forall t\right)$. I solve for the steady state with variables in efficiency units $\left(s_{t} \equiv \frac{S_{t}}{X_{t} N_{t}^{y}}, \forall s_{t}\right)$. 


\section{3}

\section{Calibration and Experiment}

The model is calibrated to match the Brazilian economy. Each period corresponds to one year. Individuals are born at the age of 20 years old. I set $\theta=0.9$ which gives individuals an average of ten years as a young worker. This is motivated by Carrasco (2019), who simulates an overlapping generations model with life-cycle wage profile to the U.S. economy and finds that marginal propensities to consume are much higher for agents between 20 and 30 years old. I set $\omega=0.9714$ which implies an average retirement age of 65 , consistent with current retirement age in Brazil.

Table 3.1: Parameter values

\begin{tabular}{lll}
\hline Parameter & Value & Target \\
\hline$\theta$ & 0.9 & Probability of remaining a young worker \\
$\omega$ & 0.9714 & Probability of remaining a mature worker \\
$\alpha$ & 0.43 & Mature labor share \\
$\eta$ & 0.23 & Young labor share \\
$\sigma$ & 0.5 & Elasticity of intertemporal substitution \\
$\delta$ & 0.05 & Depreciation rate \\
$\beta$ & 0.9610 & Individual discount factor \\
$R^{f}$ & 0.97 & Gross return on compulsory savings \\
$\tau_{t}^{w}$ & 0.07 & Income tax (\% of total income) \\
$\tau_{t}^{s s}$ & 0.20 & Social security tax (\% of total income) \\
$\tau_{t}^{f}$ & 0.08 & Compulsory savings (\% of total income) \\
$\mu$ & 0.46 & Mass of consumption-savings young workers \\
$\phi$ & 0.97 & Share of non-subsidized capital.
\end{tabular}

The social security tax and the compulsory savings tax are set in line with Brazilian legislation. I calibrate the income tax following federal government's calculations for its average effective rate. The final rate of income deductions is 0.35 , which is close to the sum of effective tax rates on income and labor in the Brazilian economy calculated by Almeida et al. (2017), equal to 0.3. The consumption tax adjusts to ensure that the government budget constraint is satisfied.

The rental rate of subsidised capital is based on data from the Central Bank of Brazil and from the National Bank of Economic and Social Development (BNDES). I follow Bonomo et al. (2016) in setting the return on compulsory savings. The share of subsidized capital is calibrated to match the ratio 
between the value of the portfolio of subsidized investments held by public banks and the stock of capital in the economy. Both of these values were converted to real terms and obtained respectively from the Institute for Applied Economic Research (IPEA) and BNDES.

The labor share of output equals 0.667 . I calibrate the values of $\alpha$ and $\eta$ to match the relative difference in average income between workers with 20 to 30 years old and workers with 30 to 65 . In mathematical terms

$$
\alpha+\eta=0.667 \quad \text { and } \quad \frac{\alpha}{\eta}=\frac{\text { Avarage Income } 30-65}{\text { Average Income } 20-30} .
$$

The elasticity of intertemporal substitution is set to 0.5 , consistent with estimates by Hall (1988) and (Yogo, 2004). The individual discount factor $\beta$ is chosen so that the real interest rate at the initial steady state equals the Brazilian real interest rate at year 2000. Finally, the mass of consumptionsavings young workers $\mu$ is calibrated such that the difference between the aggregate MPC of young workers and the MPC of retirees matches empirical estimates. In particular, Jappelli and Pistaferri (2014) find that the MPC of credit constrained agents can be 29,3 percentage points higher than that of unconstrained agents.

The experiment consists of simulating a transition between two steady states. In the initial steady state, productivity growth and the ratios of public debt to GDP, social security spending to GDP and government consumption to GDP are set to match their real values in 2000. In the final steady state, those variables are set to match their counterparts in 2019. The whole path of those variables between 2000 and 2019 was included in the simulations, not only initial and final values.

Table 3.2: Steady state exogenous variables

\begin{tabular}{lll}
\hline Parameter & Initial Value & Final Value \\
\hline Public Debt (\% GDP) & 0.66 & 0.89 \\
Social Security Spending (\% GDP) & 0.056 & 0.086 \\
Government Consumption (\% GDP) & 0.188 & 0.203 \\
Population Growth & 0.02 & -0.013 \\
Probability of Surviving $(\gamma)$ & 0.8426 & 0.9055 \\
Productivity Growth $(x)$ & 1.003 & 0.997
\end{tabular}

Initial values of population growth $n$ and surviving probability $\gamma$ were set to match the actual values of the ratios $\psi^{y, w} \equiv N^{w} / N^{y}$ and $\psi^{w, r} \equiv N^{r} / N^{w}$ in the year 2000, based on data from the Brazilian Institute of Geography and Statistics (IBGE). I also assume that $n_{t}$ and $\gamma_{t}$ follow

$$
n_{t}=n_{2000} \exp \left(u_{n t}-v_{n t}\right)
$$




$$
\gamma_{t}=\gamma_{2000} \exp \left(u_{\gamma t}-v_{\gamma t}\right)
$$

where $u_{i t}$ and $v_{i t}$ (for $i=\{n, \gamma\}$ ) are stationary $\operatorname{AR}(1)$ process with common innovation $\epsilon_{i t}$. I choose the persistence parameters $\rho_{i}$ and the initial innovation (the only unanticipated shock) such that the implied process for $\psi^{y, w}$ and $\psi^{w, r}$ match the actual data.
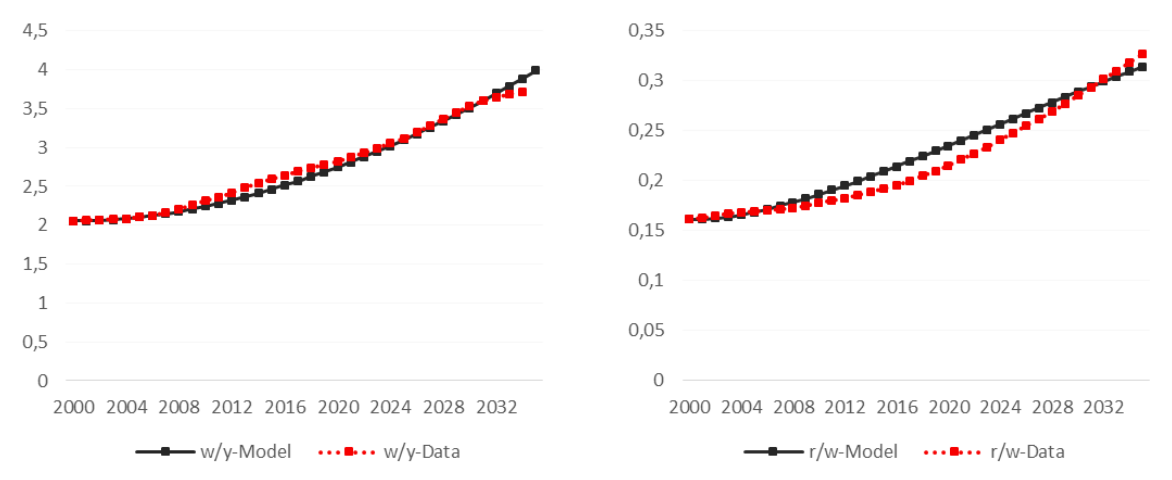

Figure 3.1: Simulated and observed trajectories for population composition

Figure 3.1 compares the evolution of $\psi^{y, w}$ and $\psi^{w, r}$ in the model with their empirical counterparts. The simulation fits the data quite well for the period under analysis. Both ratios have been increasing since 2000 and are expected to continue in a rising trend. This scenario leads to opposing forces acting on real interest rates. While a higher share of mature workers inside the labor force increases aggregate per capita savings among workers, a higher ratio of retirees to mature workers forces per capita savings down. Of course, increasing life expectancy also pushes interest rates down by augmenting savings for retirement. 


\section{4 \\ Results}

The simulated path for real interest rates is depicted in Figure 4.1. The dark line shows the main result: simulated real interest rates fall by approximately four percentage points between 2000 and 2019, as an overall result of changes in demographic variables, productivity growth, social security spending, government consumption and public debt.

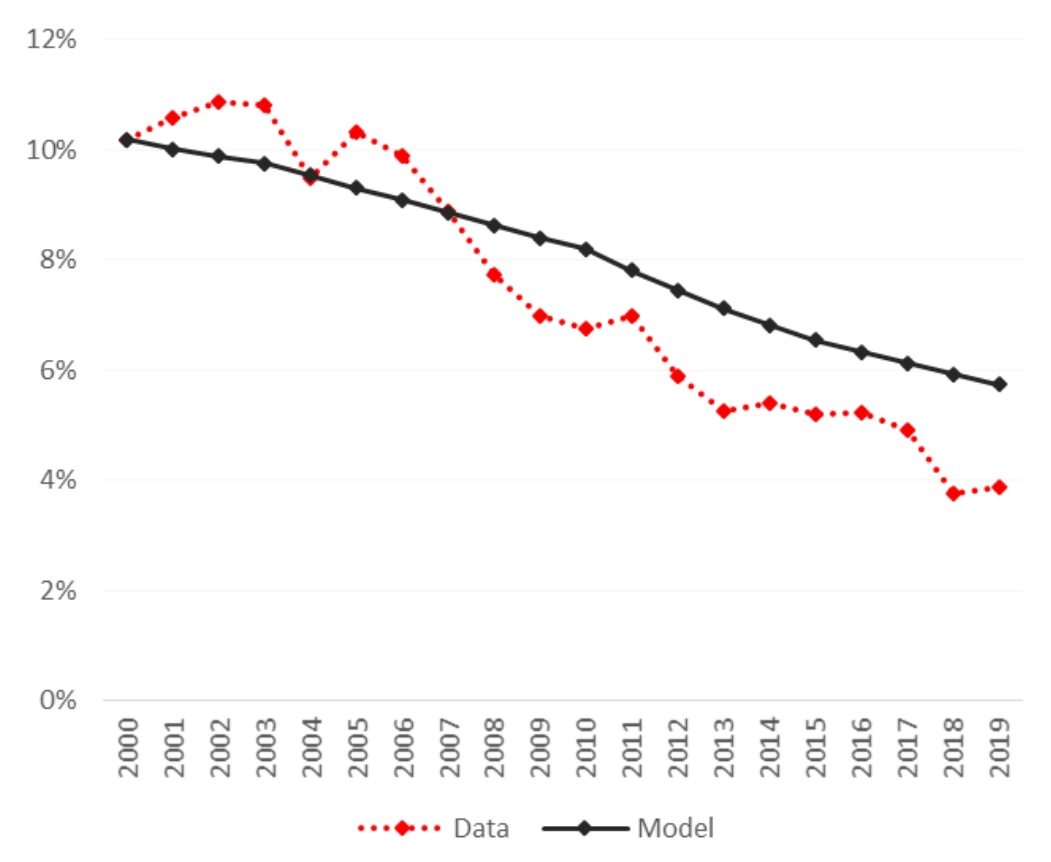

Figure 4.1: Simulated and observed trajectories for real interest rates in Brazil between 2000 and 2019

The model accounts for $70,6 \%$ of the observed variation in real interest rates in Brazil since 2000. This result is even stronger considering the modelling choices. The model is a closed economy, where the dynamics of interest rates are determined exclusively by internal factors. However, in a open economy environment, international interest rates may affect domestic interest rates. Particularly, it is likely that the recent fall in foreign interest rates has dragged down Brazilian interest rates with it. Hence, part of the variation not explained by the model may be due to this open economy effect.

The model also describes other important moments in the data. Figure 4.2 shows that the simulated paths for consumption and investment as a share 
of GDP are close to the actual performance of those variables between 2000 and 2019. Moreover, the average consumption tax rate in my simulation was 20,6\%, in line with Almeida et al. (2017), who estimate an average effective consumption tax rate of 21,9\% between 1997 and 2013 .
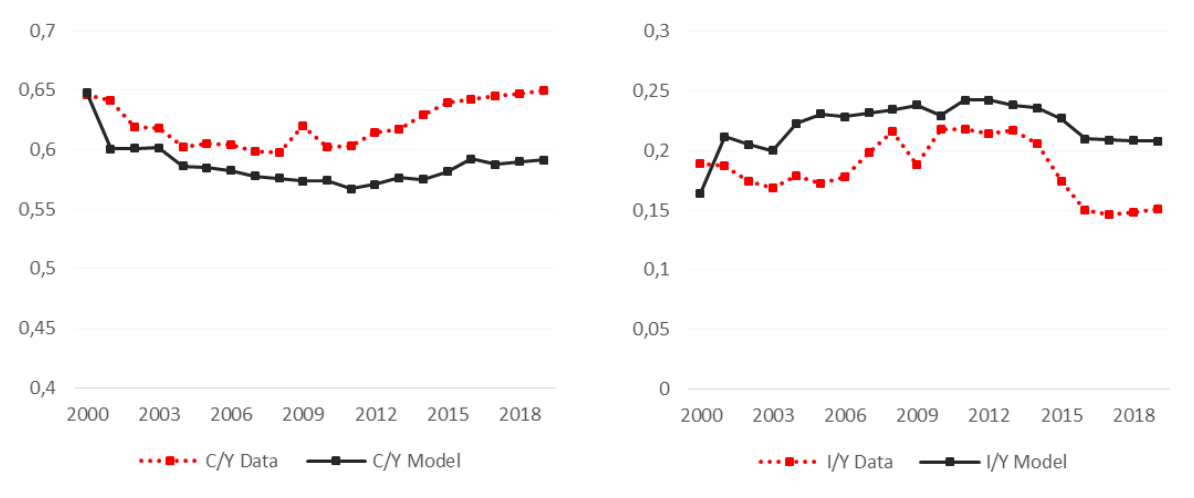

Figure 4.2: Simulated and observed trajectories for the shares of consumption and investment to GDP

To capture the partial effects of demography, productivity growth, social security, government consumption and public debt, I perform the following exercise: for each of those variables, I simulate the path for interest rates between 2000 and 2019 considering that all other exogenous variables remain constant at their initial level. As a result, I get a simulation of what would happen if only one of these variables moved.

Results are depicted in Figure 4.3. Demographic variables are the main drivers of interest rates in the period. Together, they are responsible for a decrease of about 4 percentage points in interest. Particularly important is the role played by increases in life expectancy, which explains $64 \%$ of the whole demographic effect.

The fall in real interest rates after increases in life expectancy is a result of a decrease in households' marginal propensities to consume. Retirees effectively discount the future at a rate $\beta \gamma_{t+1}$. Hence, an increase in life expectancy raises retirees' discount factor, making them save a higher share of their wealth. Since, at each period, mature workers attach a positive probability to retirement, they will also save more due to their continuation value. The same is valid for C-S young workers, who attach a positive probability to becoming mature workers.

The slowdown in population growth drives interest rates down through two mechanisms. First, it increases the share of mature workers in the labor force, which leads to more savings per capita, since mature workers have higher MPC. Second, it also increases the capital labor ratio, which diminishes the marginal productivity of capital, dragging interest rates down. The third possible effect of the population slowdown would be to increase interest rates 


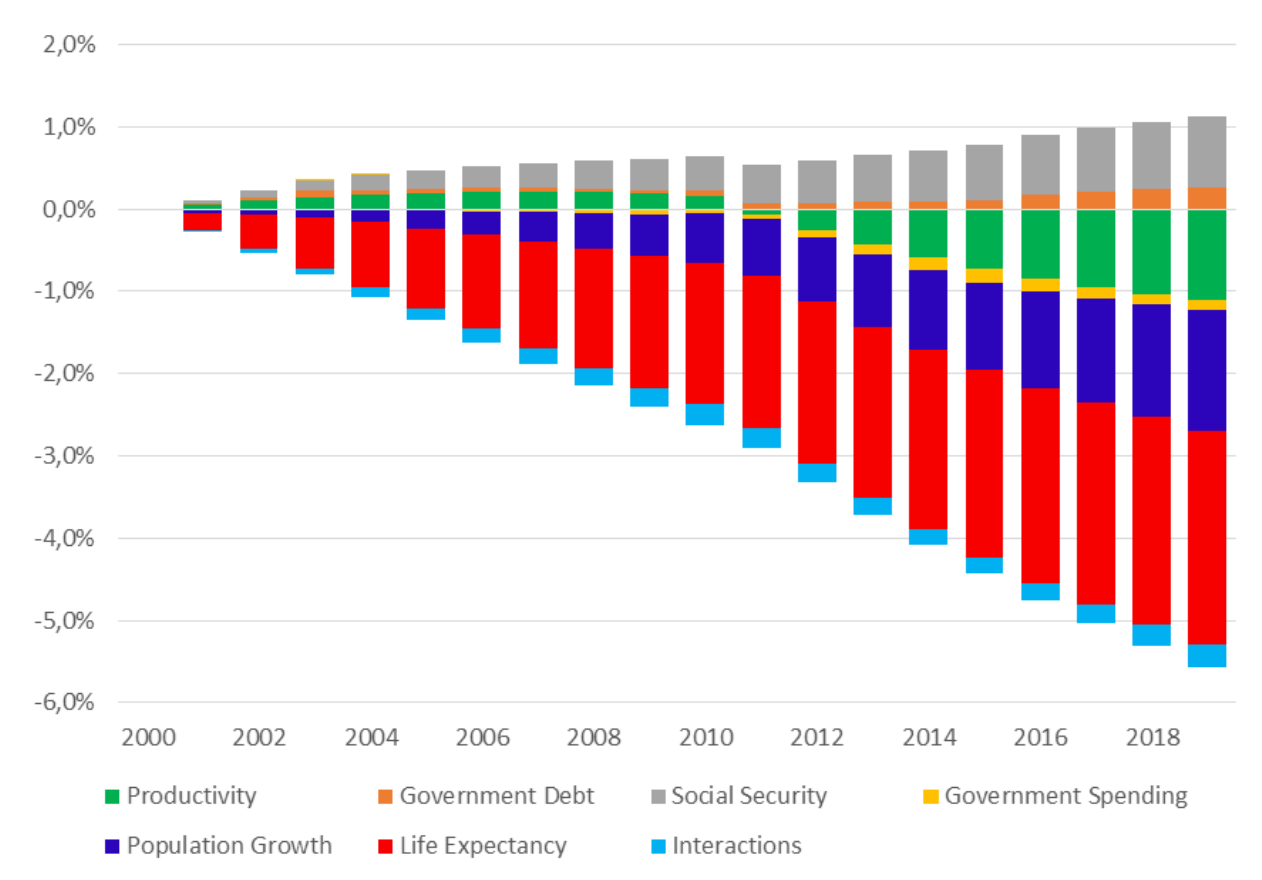

Figure 4.3: Changes in the equilibrium real interest rate as a result of policy, demographic and technological changes

by raising the dependency ratio. However, this positive effect seems to be more than compensated by the first two in my simulations.

The fall in productivity growth is also an important factor, as it solely accounts for a 1.1 percentage point decrease in interest rates, which is $25 \%$ of the variation caused by demography. This result also seems to be backed by the literature. (Eggertsson et al., 2019) used a large-scale overlapping generations model to make a similar decomposition for the U.S. economy between 1970 and 2015. They find that the effect of the productivity slowdown on interest rates is about half of the demographic effect, which is twice the size of my results. However, Brazil is passing through a much faster demographic transition than the United States. As an illustration, while life expectancy in the U.S. increased from 70 to 78 years old between 1970 and 2015, the same variable in Brazil increased from 69 to 76 years old between 2000 and 2019 - virtually the same variation in half the time. At the same time, the productivity slowdown was less drastic in Brazil, as productivity growth felt from $0.8 \%$ to $0.3 \%$ between 2000 and 2019 (in ten year averages). In the U.S. productivity growth felt from $2.8 \%$ to $0.9 \%$ between 1970 and 2015 .

The negative effect of demography and productivity is partially balanced by the growth of public debt and social security spending as a share of GDP. The latter is especially relevant, as it accounts for an increase of almost one percentage point in interest rates.

The relatively modest role played by public debt may have two reasons. 
First, this variable remained relatively stable around $65 \%$ of GDP during the first 14 years of the sample. Only in the last five years, there has been a considerable increase and public debt ascended to $89 \%$ of GDP in 2019. Second, I do not account for the risk of default. In my analysis, public debt affects interest rates only by being a burden in the government budget constraint. If I were to include a risk premium on sovereign bonds in the model, it is likely that the recent increase in public debt would have put positive pressure on real interest rates in the last years of the analysis.

\section{1}

\section{Alternative Calibrations}

As robustness checks, I repeat the simulation above, but changing two possibly sensitive calibration choices. First, I set the consumption tax rate to $22 \%$, in line with estimates for the Brazilian economy (Almeida et.al., 2017), and let the social security tax adjust to satisfy the government's budget constraint.

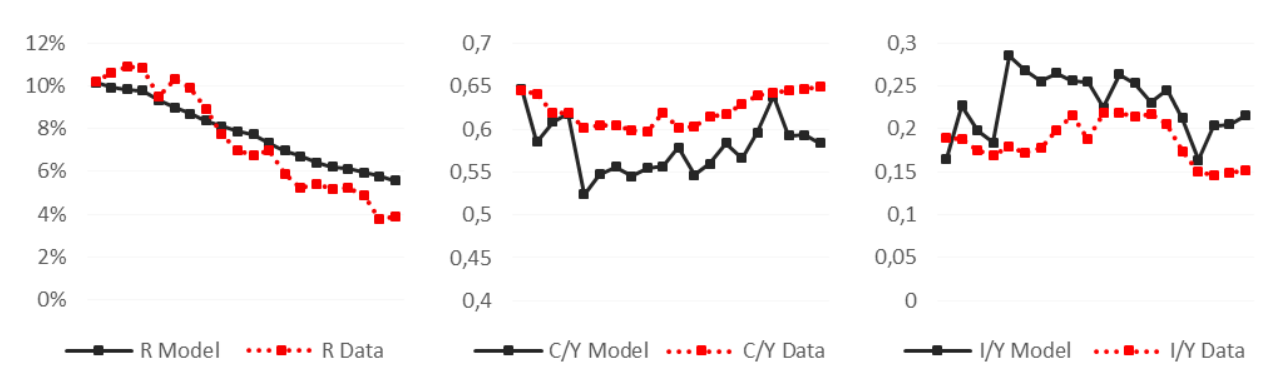

Figure 4.4: Endogenous social security tax. Fixed consumption tax rate.

As shown in Figure 4.4, results are very similar. The simulation explains $72,5 \%$ of the overall change in interest rates and fits the actual data for consumption and investment as a share of GDP. The higher volatility of consumption and investment was expected, since current available income will vary more, with the frequent fluctuations in income deductions. Finally, the average income deduction rate is $30 \%$, very close to the $31 \%$ estimated by Almeida et al. (2017).

The second robustness check was a simulation where almost every young worker is hand-to-mouth. I set $\mu=0.05$ and adjust the value of $\beta$ such that the initial interest rate fits the actual 2000 value.

Results are shown in Figure 4.5. The simulation captures $90 \%$ of the actual variation in interest rates. This improvement is explained by the labor force composition effect. Since young workers are all hand-to-mouth, a decrease in population growth will greatly increase per capita savings among workers 


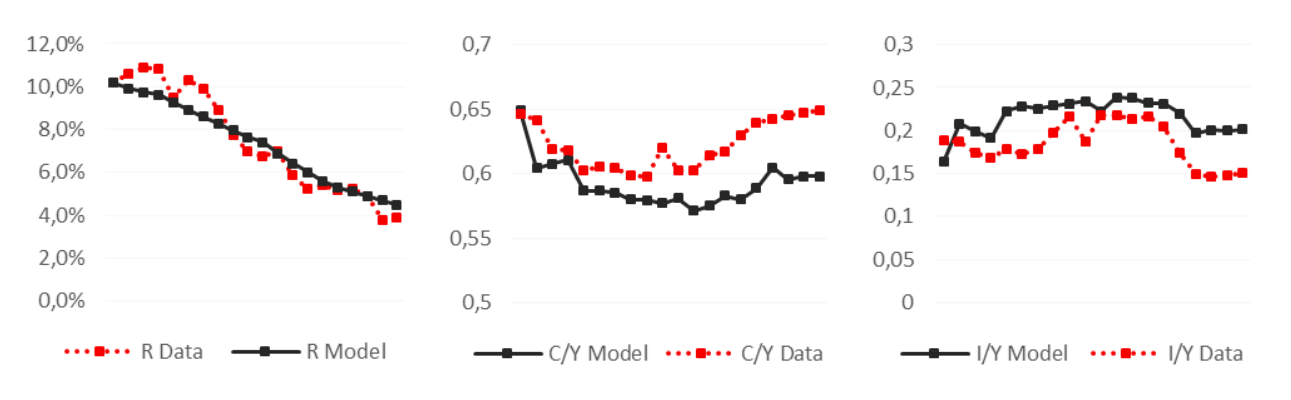

Figure 4.5: $\mu=0.05$.

by raising the ratio $N_{t}^{w} / N_{t}^{y}$. However, this improvement comes at the expenses of a slightly worse fit of simulated consumption/GDP and investment/GDP to actual data.

It is important to highlight that, everything else equal, more credit constrained workers would increase steady state real interest rates by reducing per capita savings. However, since $\beta$ was adjusted to equate the initial interest rate with actual 2000 data, this effect is not seen in the analysis.

\section{2}

\section{The importance of credit constrained young workers}

In this subsection, I compare the results I have so far with the ones obtained from a version of the model that does not include young workers. This simpler version is close to the original model by Gertler (1999) that has become standard in the literature.

There are only two kinds of households: workers and retirees. Agents are born as workers and have a constant probability of retirement. They do not face any credit constraint and are able to smooth consumption freely over their life-cycle. After retirement, they face a constant probability of surviving each period. Calibration remained roughly the same as before and only demographic parameters were adapted. The stochastic process for the surviving probability $\gamma_{t}$ is chosen so that the dependency ratio in the model fits actual data. Since there is no need to match data for the labor force composition (because workers are all the same), I included the actual path of population growth $n_{t}$ in the model.

Results are depicted in Figure 4.6. The model explains only $49 \%$ of the total variation in real interest rates. This poorer performance is explained by the shut down of the labor force composition channel. In the original framework, the slowdown in population growth pushed interest rates down by raising the capital-labor ratio and by increasing per capita savings within the labor force. This last mechanism relied on the fact that the ratio between 


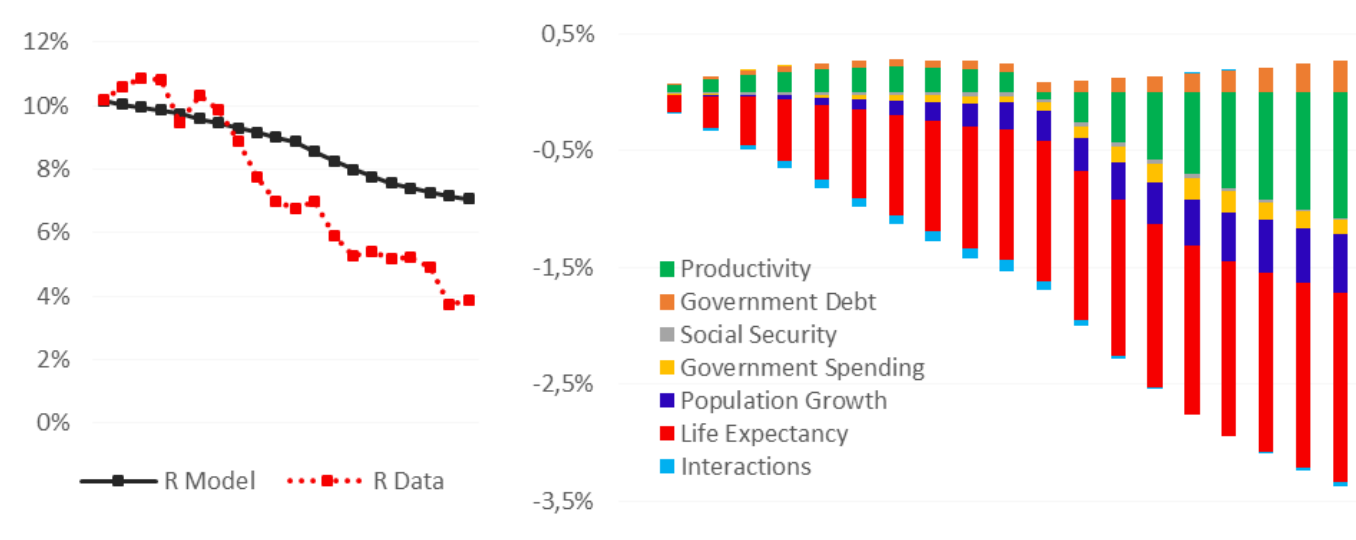

Figure 4.6: Model without young workers and credit constraints

mature and young workers would increase, resulting in a lower aggregate MPC among workers. Without heterogeneity in the labor force, every worker has the same MPC and the aggregate MPC of the labor force is not affected by population growth.

The weaker effect of the population slowdown on interest rates is manifest in the decomposition presented in Figure 4.6. While demography is still the main force driving interest rates down, this is mainly caused by increases in life expectancy, which now accounts for $76 \%$ of the entire demographic effect. This result is in line with the findings in Carvalho, Ferrero and Nechio (2016), who simulated a simpler version of the model for a group of advanced economies. Without taking heterogeneity among workers into account, they found that increases in life-expectancy were responsible for $86 \%$ of the effect of demography on real interest rates.

These comparisons reinforce the need for including labor force heterogeneity when analysing the effects of demography on real interest rates. Only very recently, authors are accounting for this aspect of the demographic transition, by building up large scale overlapping generation models with a life cycle wage profile (Carrasco, 2019; Eggertsson et al., 2019). Particularly, (Carrasco, 2019) argues that this heterogeneity is essential for explaining the hump shape path of real interest rates in the U.S. Economy since the 1950's. However, those models are much more computationally demanding. In Appendix B, I show how my model is capable of obtaining a similar hump-shape path for interest rates, despite being much more friendly in terms of computation.

\section{3}

\section{Projections}

I run the model to simulate the path of real interest rates in Brazil for the next 20 years. The initial value for the real interest rate is set 
equal to its observed value in 2020. Demographic variables are assumed to follow projections made by the Brazilian Institute of Geography and Statistics (IBGE). Social security spending as a share of GDP is fixed at 2020 levels. The trajectory for public debt is based on projections made by the Brazilian National Treasury in July 2020 and shown in Figure 4.7. Since there are projection values only for the next ten years, I assume the debt will gradually return to its 2019 level between 2030 and 2040.

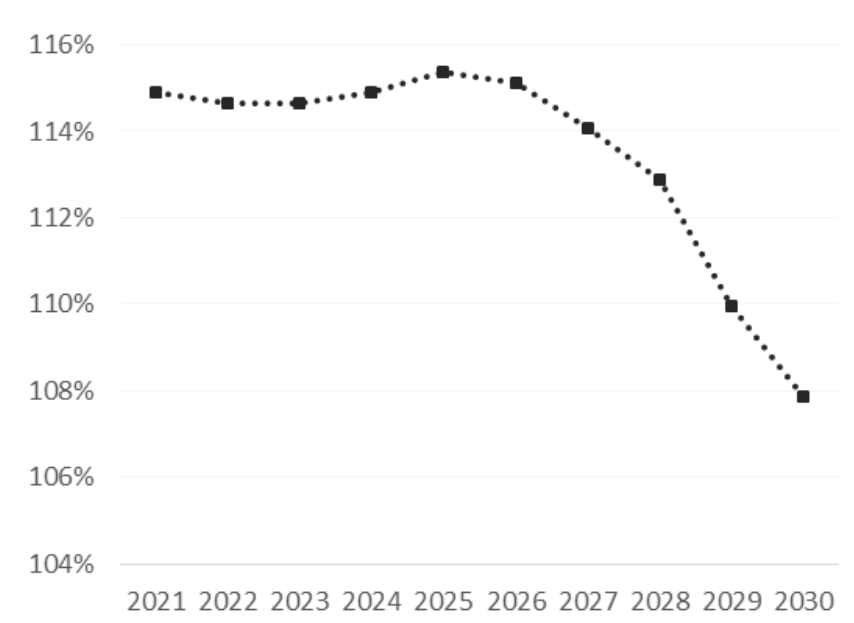

Figure 4.7: Projected debt to GDP ratio between 2021 and 2030

Results are presented in Figure 4.8. The model projects that the demographic transition will likely keep pushing real interest rates down with a total variation of 2.1 percentage points over the next 20 years, reaching a level of $1.5 \%$. However, this findings must be interpreted carefully, since I do not model the risk of sovereign default. If this important determinant was included in the analysis, real interest rates would certainly not fall as much, since Brazilian debt to GDP ratio is increasing rapidly.

\section{4}

\section{Structural Reform}

The growth of productivity in Brazil has been abnormally low in the last twenty years, considering the average of developing countries. As a last exercise, I investigate the effects of an unspecified reform that increases productivity growth. More specifically, I use the model to find what is the growth rate of productivity necessary to keep interest rates constant over the next 20 years.

Results show that, if productivity grew around $3 \%$ a year, interest rates would remain at its current level. Despite seeming optimistic for Brazilian standards, this outcome indicates that the increase in productivity growth necessary to counteract demographic (and other) forces that put downward 


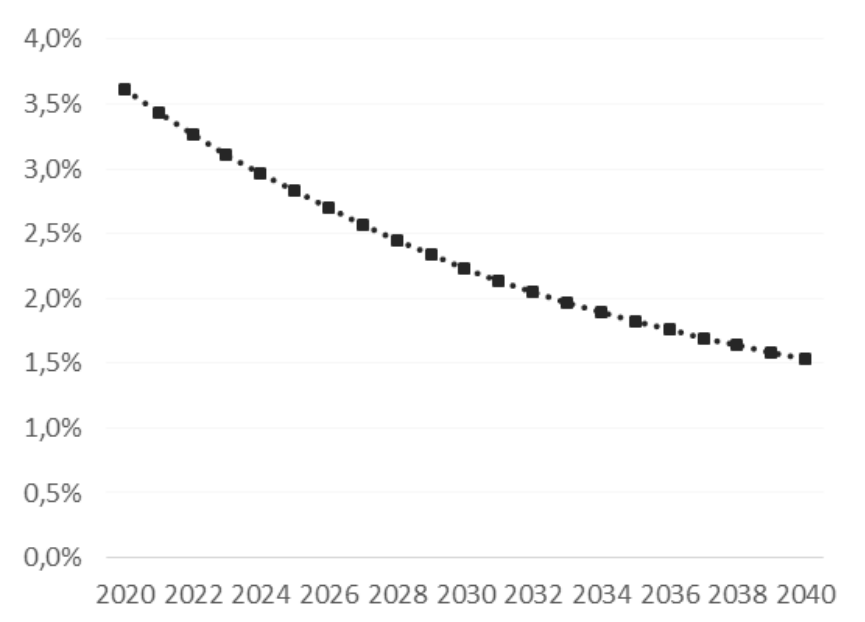

Figure 4.8: Projected real interest rates between 2020 and 2040

pressure on the real interest rate is not massive. In fact, a $2 \%$ growth rate of productivity is not far from the average for developing economies in recent periods. 


\section{5}

\section{Conclusion}

Real interest rates have been falling in Brazil since the beginning of the century. This phenomenon is in line with the downward trend in interest rates observed in advanced economies since the 1990's, encouraging the study of long-term determinants of this variable.

Several long-term drivers played an important role in the recent downward trend in Brazilian real interest rates. While demography and low productivity growth were the most important factors pushing interest rates down, social security spending and public debt were important balancing forces. Moreover, the effects of lower population growth are augmented after including the credit constraints faced by young workers. This generates the so called labor force composition effect, an element frequently ignored in the literature.

Together, movements in demographic variables, productivity growth, government consumption, social security spending and public debt explained around $71 \%$ of the overall decrease in Brazilian interest rates between 2000 and 2019. Great part of the remaining variation is probably caused by downward movements in world interest rates and increases in inequality. Future research will include both of these drivers in the model.

Real interest rates in Brazil will probably keep falling over the next 20 years due to the demographic transition. This trend seems to be resistant to plausible increases in public debt, but ignores possible risk premia effects. An economic reform that manages to increase productivity growth rates to little more than $3 \%$ per year may balance this trend and keep interest rates at its current level. 


\section{Bibliography}

Almeida, V., Divino, J. A., Gadelha, S. R. d. B., and Maranhão, A. (2017). Alíquotas tributárias efetivas médias para a economia brasileira: uma abordagem macroeconômica. Revista Brasileira de Economia, 71(2):153-175.

Blanchard, O. J. (1985). Debt, Deficits, and Finite Horizons. Journal of Political Economy, 93(2):223-247.

Bonomo, M., Brito, R. D., and dos Santos, M. R. (2016). Why are savings rates so low and interest rates so high in brazil? the role of unfunded social security and compulsory savings. In 38th Meeting of the Brazilian Econometric Society.

Brito, R. D. and Carvalho, C. (2015). Macroeconomic effects of the demographic transition in brazil. In Asymmetric Demography and the Global Economy, pages 151-185. Springer.

Carrasco, A. (2019). Demographics and real interest rate in the u.s. economy. Dissertação de mestrado, Departamento de Economia, Pontifícia Universidade Católica do Rio de Janeiro, Rio de Janeiro.

Carvalho, C., Ferrero, A., and Nechio, F. (2016). Demographics and real interest rates: Inspecting the mechanism. European Economic Review, 88:208-226.

Eggertsson, G. B., Mehrotra, N. R., and Robbins, J. A. (2019). A model of secular stagnation: Theory and quantitative evaluation. American Economic Journal: Macroeconomics, 11(1):1-48.

Epstein, L. G. and Zin, S. E. (1989). Substitution, risk aversion, and the temporal behavior of consumption and asset returns: a theoretical framework. Econometrica, 57:937-969.

Fagereng, A., Holm, M. B., and Natvik, G. J. J. (2019). Mpc heterogeneity and household balance sheets. Available at SSRN 3399027.

Ferrero, A. (2010). A structural decomposition of the us trade balance: Productivity, demographics and fiscal policy. Journal of Monetary Economics, 57(4):478490. 
Gertler, M. (1999). Government debt and social security in a life-cycle economy. In Carnegie-Rochester Conference Series on Public Policy, volume 50, pages 61-110. Elsevier.

Gourinchas, P.-O. and Rey, H. (2014). External adjustment, global imbalances, valuation effects. In Handbook of international economics, volume 4, pages 585-645. Elsevier.

Hall, R. E. (1988). Intertemporal substitution in consumption. Journal of political economy, 96(2):339-357.

Jappelli, T. and Pistaferri, L. (2014). Fiscal policy and mpc heterogeneity. American Economic Journal: Macroeconomics, 6(4):107-36.

Kreps, D. M. and Porteus, E. L. (1978). Temporal resolution of uncertainty and dynamic choice theory. Econometrica: journal of the Econometric Society, pages 185-200.

Summers, L. H. and Rachel, L. (2019). On falling neutral real rates, fiscal policy and the risk of secular stagnation. In Brookings Papers on Economic Activity BPEA Conference Drafts, March, pages 7-8.

Yaari, M. E. (1965). Uncertain lifetime, life insurance, and the theory of the consumer. The Review of Economic Studies, 32(2):137-150.

Yogo, M. (2004). Estimating the elasticity of intertemporal substitution when instruments are weak. Review of Economics and Statistics, 86(3):797-810. 
A

\section{Model Solution}

In this appendix, I present a step-by-step solution of the households' problems.

\section{A.1}

\section{Retirees}

An individual who was born in period $i$, became a mature worker in period $j$ and retired in period $k$ will choose consumption $C_{t}^{r}(i, j, k)$ and assets $A_{t}^{r}(i, j, k)$, for $t \geq k$ to solve

$$
V_{t}^{r}(i, j, k)=\max \left\{\left(C_{t}^{r}(i, j, k)\right)^{\rho}+\gamma_{t+1} \beta\left[V_{t+1}^{r}(i, j, k)\right]^{\rho}\right\}^{\frac{1}{\rho}},
$$

subject to

$$
\left(1+\tau_{t}^{c}\right) C_{t}^{r}(i, j, k)+A_{t}^{r}(i, j, k)=\frac{R_{t-1} A_{t-1}^{r}(i, j, k)}{\gamma_{t}}+E_{t}^{r} .
$$

The first order condition with respect to retirees's asset holdings is

$$
\left(C_{t}^{r}(i, j, k)\right)^{\rho-1}=\left(1-\tau_{t}^{c}\right) \gamma_{t+1} \beta\left[V_{t+1}^{r}(i, j, k)\right]^{\rho-1} \frac{\partial V_{t+1}^{r}(i, j, k)}{\partial A_{t}^{r}(i, j, k)} .
$$

The Envelope Theorem conditions are

$$
\frac{\partial V_{t}^{r}(i, j, k)}{\partial A_{t-1}^{r}(i, j, k)}=\frac{\left[V_{t}^{r}(i, j, k)\right]^{1-\rho}\left(C_{t}^{r}(i, j, k)\right)^{\rho-1} R_{t-1}}{\gamma_{t}\left(1-\tau_{t}^{c}\right)} .
$$

Combining these two optimality condition yields the Euler Equation

$$
C_{t+1}^{r}(i, j, k)=\left[R_{t} T_{t+1} \beta\right]^{\sigma} C_{t}^{r}(i, j, k),
$$

where $\sigma=\frac{1}{1-\rho}$ and $T_{t+1} \equiv\left(1+\tau_{t}^{c}\right) /\left(1+\tau_{t+1}^{c}\right)$. To solve the problem of retirees, guess that consumption is a fraction of total wealth

$$
C_{t}^{r}(i, j, k)=\xi_{t}^{r}\left[\frac{R_{t-1} A_{t-1}^{r}(i, j, k)}{\gamma_{t}}+S_{t}^{r}\right],
$$

where $S_{t}^{r}$ stands for the present value of total social security benefits received by a retiree 


$$
S_{t}^{r}=\sum_{v=0}^{\infty}\left\{\frac{E_{t+v}^{r}}{\prod_{s=0}^{v} \frac{R_{t-1+s}}{\gamma_{t+s}}}\right\}=E_{t}^{r}+\frac{\gamma_{t+1} S_{t+1}^{r}}{R_{t}}
$$

Substitute the guess (A-2) into the budget constraint and use the last term of the definition (A-3) to get

$$
A_{t}^{r}+\frac{\gamma_{t+1} S_{t+1}^{r}}{R_{t}}=\left[1-\left(1+\tau_{t}^{c}\right) \xi_{t}^{r}\right]\left[\frac{R_{t-1} A_{t-1}^{r}(i, j, k)}{\gamma_{t}}+S_{t}^{r}\right] .
$$

Substituting the guess (A-2) into the Euler Equation (A-1) leads to

$$
\xi_{t+1}^{r}\left[A_{t}^{r}+\frac{\gamma_{t+1} S_{t+1}^{r}}{R_{t}}\right]=\gamma_{t+1} R_{t}^{\sigma-1}\left(\beta T_{t+1}\right)^{\sigma} \xi_{t}^{r}\left[\frac{R_{t-1} A_{t-1}^{r}(i, j, k)}{\gamma_{t}}+S_{t}^{r}\right] .
$$

Combining the last two equations yields a first-order non-linear difference equation for the retirees' marginal propensity to consume out of wealth $\xi_{t}^{r}$

$$
\frac{1}{\xi_{t}^{r}}=\left(1+\tau_{t}^{c}\right)+\gamma_{t+1} R_{t}^{\sigma-1}\left(\beta T_{t+1}\right)^{\sigma} \frac{1}{\xi_{t+1}^{r}} .
$$

Furthermore, conjecture that the retiree's value function is linear in current consumption

$$
V_{t}^{r}(i, j, k)=\Delta_{t}^{r} C_{t}^{r}(i, j, k)
$$

Substituting this conjecture into the retiree's objective function leads to

$$
\left[\left(\Delta_{t}^{r}\right)^{\rho}-1\right]\left(C_{t}^{r}(i, j, k)\right)^{\rho}=\gamma_{t+1} \beta\left[\Delta_{t+1}^{r} C_{t+1}^{r}(i, j, k)\right]^{\rho} .
$$

Using the Euler Equation one finds

$$
\left(\Delta_{t}^{r}\right)^{\rho}=1+\gamma_{t+1}\left(T_{t+1} R_{t}\right)^{\sigma-1} \beta^{\sigma}\left(\Delta_{t+1}^{r}\right)^{\rho} .
$$

Finally, (A-6) and (A-9) imply

$$
\Delta_{t}^{r}=\left[\xi_{t}^{r}\left(1+\tau_{t}^{c}\right)\right]^{-\frac{1}{\rho}}
$$

\section{A.2 \\ Mature Workers}

An individual who was born in period $i$ and aged for the first time in period $j$ chooses consumption $C_{t}^{w}(i, j)$ and assets $A_{t}^{w}(i, j)$ to solve

$$
V_{t}^{w}(i, j)=\max \left\{\left(C_{t}^{w}(i, j)\right)^{\rho}+\beta\left[\omega_{t+1} V_{t+1}^{w}+\left(1-\omega_{t+1}\right) V_{t+1}^{r}\right]^{\rho}\right\}^{\frac{1}{\rho}}
$$

subject to

$$
\begin{gathered}
\left(1+\tau_{t}^{c}\right) C_{t}^{w}(i, j)+A_{t}^{w}(i, j)=R_{t-1} A_{t-1}^{w}(i, j)+W_{t}^{w}\left[1-\tau_{t}\right] \\
F_{t}^{w}(i, j)=R_{t-1}^{f} F_{t-1}^{w}(i, j)+\tau_{t}^{f} W_{t}^{w}
\end{gathered}
$$


The first order condition for workers' asset holdings is

$$
\left(C_{t}^{w}(i, j)\right)^{\rho-1}=\left(1+\tau_{t}^{c}\right) \beta\left[\omega_{t+1} V_{t+1}^{w}+\left(1-\omega_{t+1}\right) V_{t+1}^{r}\right]^{\rho-1}\left[\omega_{t+1} \frac{\partial V_{t+1}^{w}}{\partial A_{t}^{w}}+\left(1-\omega_{t+1}\right) \frac{\partial V_{t+1}^{r}}{\partial A_{t}^{w}}\right] .
$$

The Envelope Theorem conditions are

$$
\begin{gathered}
\frac{\partial V_{t}^{w}(i, j)}{\partial A_{t-1}^{w}}=\left(V_{t}^{w}(i, j)\right)^{1-\rho}\left(C_{t}^{w}(i, j)\right)^{\rho-1}\left[\frac{R_{t-1}}{\left(1+\tau_{t}^{c}\right)}\right], \\
\frac{\partial V_{t}^{r}(i, j)}{\partial A_{t-1}^{w}}=\frac{\partial V_{t}^{r}(i, j)}{\partial A_{t-1}^{r}} \frac{\partial A_{t-1}^{r}(i, j)}{\partial A_{t-1}^{w}(i, j)}=\left(V_{t}^{r}(i, j)\right)^{1-\rho}\left(C_{t}^{r}(i, j)\right)^{\rho-1}\left[\frac{R_{t-1}}{\left(1+\tau_{t}^{c}\right)}\right],
\end{gathered}
$$

where the second equality in the last equation follows from the fact that

$$
A_{t-1}^{r}(i, j)=A_{t-1}^{w}(i, j)+F_{t-1}^{w}(i, j)
$$

Plugging the Envelope Theorem equations into the first order condition yields the Euler Equation

$$
\begin{array}{r}
\left(C_{t}^{w}(i, j)\right)^{\rho-1} T_{t+1}=R_{t} \beta\left[\omega_{t+1} V_{t+1}^{w}+\left(1-\omega_{t+1}\right) V_{t+1}^{r}\right]^{\rho-1} \\
{\left[\omega_{t+1}\left(V_{t}^{w}(i, j)\right)^{1-\rho}\left(C_{t}^{w}(i, j)\right)^{\rho-1}\right.} \\
\left.+\left(1-\omega_{t+1}\right)\left(V_{t}^{r}(i, j, t+1)\right)^{1-\rho}\left(C_{t}^{r}(i, j, t+1)\right)^{\rho-1}\right] .
\end{array}
$$

To solve the problem of mature workers, conjecture that their value function is linear in current consumption, just like for retirees in (A-7).

$$
V_{t}^{w}(i, j)=\Delta_{t}^{w} C_{t}^{w}(i, j)
$$

Substituting this conjecture into the Euler Equation, together with (51) leads to

$$
\begin{array}{r}
\left(C_{t}^{w}(i, j)\right)^{\rho-1} T_{t+1}=R_{t} \beta\left[\omega_{t+1} \Delta_{t+1}^{w} C_{t+1}^{w}(i, j)+\left(1-\omega_{t+1}\right) \Delta_{t+1}^{r} C_{t+1}^{r}(i, j)\right]^{\rho-1} \\
{\left[\omega_{t+1}\left(\Delta_{t+1}^{w}\right)^{1-\rho}+\left(1-\omega_{t+1}\right)\left(\Delta_{t+1}^{r}\right)^{1-\rho}\right]}
\end{array}
$$

Defining $\Omega_{t} \equiv \omega_{t}+\left(1-\omega_{t+1}\right) \frac{\Delta_{t}^{r}}{\Delta_{t}^{w}}$, the Euler equation becomes

$$
\omega_{t+1} C_{t+1}^{w}(i, j)+\left(1-\omega_{t+1}\right) \frac{\Delta_{t+1}^{r}}{\Delta_{t+1}^{w}} C_{t+1}^{r}(i, j)=\left[R_{t} \Omega_{t+1} T_{t+1} \beta\right]^{\sigma} C_{t}^{w}(i, j) .
$$

As for the retirees, guess that consumption is a fraction of total wealth

$$
C_{t}^{w}(i, j)=\xi_{t}^{w}\left[A_{t-1}^{w}(i, j) R_{t-1}+H_{t}^{w}+S_{t}^{w}+\mathcal{F}_{t}^{w}\right]
$$


where $H_{t}^{w}$ represents the present discounted value of current and future real wages net of income and lump-some taxation for a mature worker

$$
H_{t}^{w}=\sum_{v=0}^{\infty}\left\{\frac{W_{t+v}^{w}\left(1-\tau_{t}\right)}{\prod_{s=0}^{v} \frac{R_{t-1+v} \Omega_{t+v}}{\omega_{t+s}}}\right\}=W_{t}^{w}\left(1-\tau_{t}\right)+\frac{\omega_{t+1} H_{t+1}^{w}}{R_{t} \Omega_{t+1}}
$$

$S_{t}^{w}$ is the present discounted value of social security benefits for a mature worker after retirement

$$
S_{t}^{w}=\sum_{v=0}^{\infty}\left\{\frac{\frac{\left(\Omega_{t+v+1}-\omega_{t+v+1}\right) S_{t+v+1}^{w}}{\Omega_{t+v+1} R_{t+v}}}{\prod_{s=0}^{v} \Omega_{t+s} R_{t-1+s}}\right\}=\frac{\left(\Omega_{t+1}-\omega_{t+1}\right) S_{t+1}^{w}}{\Omega_{t+1} R_{t}}+\frac{\omega_{t+1} S_{t+1}^{w}}{\Omega_{t+1} R_{t}} .
$$

$\mathcal{F}_{t}^{w}$ is the present discounted value of the FGTS benefits received after retirement for a mature worker

$$
\mathcal{F}_{t}^{w}=\frac{\omega_{t+1} \mathcal{F}_{t+1}^{w}}{R_{t} \Omega_{t+1}}+\frac{\Omega_{t+1}-\omega_{t+1} F_{t}^{r}}{R_{t} \Omega_{t+1}} .
$$

Substituting the guess (56) into the budget constraint and using definition (57) yields

$$
\begin{aligned}
A_{t}^{w}(i, j)+S_{t}^{w} & +\mathcal{F}_{t}^{w}+\frac{\omega_{t+1} H_{t+1}^{w}}{\Omega_{t+1} R_{t}} \\
= & {\left[1-\left(1+\tau_{c}\right) \xi_{t}^{w}\right]\left[A_{t-1}^{w}(i, j) R_{t-1}+H_{t}^{w}+S_{t}^{w}+\mathcal{F}_{t}^{w}\right] . }
\end{aligned}
$$

Substituting the guess into the Euler equation results in

$$
\begin{aligned}
\omega_{t+1} \xi_{t}^{w}\left[A_{t}^{w}(i, j)\right. & \left.R_{t}+H_{t+1}^{w}+S_{t+1}^{w}+\mathcal{F}_{t+1}^{w}\right] \\
+ & \left(1-\omega_{t+1}\right) \frac{\Delta_{t+1}^{r}}{\Delta_{t+1}^{w}}\left[A_{t}^{r}(i, j) R_{t}+S_{t+1}^{r}+F_{t+1}^{w}\right] \\
= & {\left[R_{t} \Omega t+1 \beta\right]^{\sigma} \xi_{t}^{w}\left[A_{t-1}^{w}(i, j) R_{t-1}+H_{t}^{w}+S_{t}^{w}+\mathcal{F}_{t}^{w}\right] . }
\end{aligned}
$$

Dividing everything by $\xi_{t+1}^{w}$ and guessing that $\xi_{t}^{w}=\left[\left(\Delta_{t}^{w}\right)^{\rho}\left(1+\tau_{t}^{c}\right)\right]^{-1}$,

$A_{t}^{w}(i, j)+S_{t}^{w}+\mathcal{F}_{t}^{w}+\frac{\omega_{t+1} H_{t+1}^{w}}{\Omega_{t+1} R_{t}}=\left[R_{t} \Omega_{t+1}\right]^{\sigma-1} \beta^{\sigma} \xi_{t}^{w}\left[A_{t-1}^{w}(i, j) R_{t-1}+H_{t}^{w}+S_{t}^{w}+\mathcal{F}_{t}^{w}\right]$,

which implies a first-order non-linear difference equation for the mature worker marginal propensity to consume out of total wealth

$$
\frac{1}{\xi_{t}^{w}}=\left(1+\tau_{t}^{c}\right)+\left[\Omega_{t+1} R_{t}\right]^{\sigma-1}\left(T_{t+1} \beta\right)^{\sigma} \frac{1}{\xi_{t}^{w}} .
$$

Substituting the guess for the value function into the the mature worker's objective function one gets

$$
\left[\left(\Delta_{t}^{w}\right)^{\rho}-1\right]\left(C_{t}^{w}(i, j)\right)^{\rho}=\beta\left[\omega_{t+1} \Delta_{t+1}^{w} C_{t+1}^{w}(i, j)+\left(1-\omega_{t+1}\right) \Delta_{t+1}^{r} C_{t+1}^{r}(i, j, t+1)\right]^{\rho}
$$


which, using the definition of the adjustment factor $\Omega_{t+1}$ yields

$$
\left(\Delta_{t}^{w}\right)^{\rho}=1+\gamma_{t+1}\left(T_{t+1} R_{t}\right)^{\sigma-1} \beta^{\sigma}\left(\Delta_{t+1}^{w}\right)^{\rho} .
$$

Finally, (A-18) and (A-19) imply

$$
\xi_{t}^{w}=\left[\left(1+\tau_{t}^{c}\right)\left(\Delta_{t}^{w}\right)^{\rho}\right]^{-1}
$$

and all the guesses are verified.

\section{A.3}

\section{Young Workers}

To simulate the effect of the credit constraints faced by young workers, a mass $(1-\mu)$ of these workers will be hand-to-mouth, i.e. will consume only their current income. The remaining $\mu$ will solve a standard consumptionsavings problem, as for mature workers and retirees.

\section{A.3.1}

\section{Consumption Savings Young Workers}

A young worker who does not face credit constraints will choose consumption $C_{t}^{c s}(i)$ and assets $A_{t}^{c s}(i)$ to solve

$$
V_{t}^{c s}(i)=\max \left\{\left(C_{t}^{c s}(i)\right)^{\rho}+\beta\left[\theta_{t+1} V_{t+1}^{c s}+\left(1-\theta_{t+1}\right) V_{t+1}^{w}\right]^{\rho}\right\}^{\frac{1}{\rho}},
$$

subject to

$$
\begin{gathered}
\left(1+\tau_{t}^{c}\right) C_{t}^{c s}(i)+A_{t}^{c s}(i)=R_{t-1} A_{t-1}^{c s}(i)+W_{t}^{y}\left[1-\tau_{t}\right] \\
F_{t}^{c s}(i)=R_{t-1}^{f} F_{t-1}^{c s}(i)+\tau_{t}^{f} W_{t}^{y}
\end{gathered}
$$

The first order condition for young workers' asset holdings is

$$
\left(C_{t}^{c s}(i)\right)^{\rho-1}=\left(1+\tau_{t}^{c}\right) \beta\left[\theta_{t+1} V_{t+1}^{c s}+\left(1-\theta_{t+1}\right) V_{t+1}^{w}\right]^{\rho-1}\left[\theta_{t+1} \frac{\partial V_{t+1}^{c s}}{\partial A_{t}^{c s}}+\left(1-\theta_{t+1}\right) \frac{\partial V_{t+1}^{w}}{\partial A_{t}^{c s}}\right]
$$

The Envelope Theorem conditions are

$$
\begin{gathered}
\frac{\partial V_{t}^{c s}(i)}{\partial A_{t-1}^{c s}}=\left(V_{t}^{c s}(i)\right)^{1-\rho}\left(C_{t}^{c s}(i)\right)^{\rho-1}\left[\frac{R_{t-1}}{\left(1+\tau_{c}\right)}\right], \\
\frac{\partial V_{t}^{w}(i, t)}{\partial A_{t-1}^{c s}}=\frac{\partial V_{t}^{w}(i, t)}{\partial A_{t-1}^{w}} \frac{\partial A_{t-1}^{w}(i, t)}{\partial A_{t-1}^{c s}(i)}=\left(V_{t}^{w}(i, t)\right)^{1-\rho}\left(C_{t}^{w}(i, t)\right)^{\rho-1}\left[\frac{R_{t-1}}{\left(1+\tau_{t}^{c}\right)}\right],
\end{gathered}
$$


where the second equality in the last equation follows from the fact that

$$
A_{t-1}^{w}(i, t)=A_{t-1}^{c s}(i)
$$

. Plugging the Envelope Theorem equations into the first order condition yields the Euler Equation

$$
\begin{aligned}
& \left(C_{t}^{c s}(i)\right)^{\rho-1} T_{t+1}=R_{t} \beta\left[\theta_{t+1} V_{t+1}^{c s}+\left(1-\theta_{t+1}\right) V_{t+1}^{w}\right]^{\rho-1} \\
& {\left[\theta_{t+1}\left(V_{t}^{c s}(i)\right)^{1-\rho}\left(C_{t}^{c s}(i)\right)^{\rho-1}+\left(1-\theta_{t+1}\right)\left(V_{t+1}^{w}(i, t+1)\right)^{1-\rho}\left(C_{t}^{w}(i, t+1)\right)^{\rho-1}\right] .}
\end{aligned}
$$

To solve the problem of non-restricted young workers, conjecture that their value function is linear in current consumption

$$
V_{t}^{c s}(i)=\Delta_{t}^{c s} C_{t}^{c s}(i)
$$

. Substituting this conjecture into the Euler Equation leads to

$$
\begin{aligned}
\left(C_{t}^{c s}(i)\right)^{\rho-1} T_{t+1}=R_{t} \beta\left[\theta_{t+1} \Delta_{t+1}^{c s} C_{t+1}^{c s}(i)+\left(1-\theta_{t+1}\right) \Delta_{t+1}^{w} C_{t+1}^{w}(i, t+1)\right]^{\rho-1} & \\
& {\left[\theta_{t+1}\left(\Delta_{t+1}^{c s}\right)^{1-\rho}+\left(1-\theta_{t+1}\right)\left(\Delta_{t+1}^{w}\right)^{1-\rho}\right] . }
\end{aligned}
$$

Defining $\Theta_{t} \equiv \theta_{t}+\left(1-\theta_{t+1}\right) \frac{\Delta_{t}^{w}}{\Delta_{t}^{c s}}$, the Euler equation becomes

$$
\theta_{t+1} C_{t+1}^{c s}(i)+\left(1-\theta_{t+1}\right) \frac{\Delta_{t+1}^{w}}{\Delta_{t+1}^{c s}} C_{t+1}^{w}(i, t+1)=\left[R_{t} \Theta_{t+1} T_{t+1} \beta\right]^{\sigma} C_{t}^{c s}(i) .
$$

As for the previous cases, guess that consumption is a fraction of total wealth

$$
C_{t}^{c s}(i)=\xi_{t}^{c s}\left[A_{t-1}^{c s}(i) R_{t-1}+H_{t}^{c s}+S_{t}^{c s}+\mathcal{F}_{t}^{c s}\right],
$$

where $H_{t}^{c s}$ represents the present discounted value of current and future real wages net of income and lump-some taxation for a young worker

$$
H_{t}^{c s}=W_{t}^{c s}\left(1-\tau_{t}\right)+\frac{\theta_{t+1} H_{t+1}^{c s}+\left[\frac{\xi_{t+1}^{w}}{\xi_{t}^{c s}}\right]^{\frac{1}{1-\sigma}}\left(1-\theta_{t+1}\right) H_{t+1}^{w}}{\Theta_{t+1} R_{t}} .
$$

$S_{t}^{w}$ is the present discounted value of social security benefits for a young worker after retirement

$$
S_{t}^{w}=\frac{\left(\Theta_{t+1}-\theta_{t+1}\right) S_{t+1}^{w}}{\Theta_{t+1} R_{t}}+\frac{\theta_{t+1} S_{t+1}^{c s}}{\Theta_{t+1} R_{t}} .
$$

$\mathcal{F}_{t}^{c s}$ is the present discounted value of the FGTS benefits received after retirement for a young worker 


$$
\mathcal{F}_{t}^{c s}=\frac{\left(\Theta_{t+1}-\theta_{t+1}\right) \mathcal{F}_{t+1}^{w}}{\Theta_{t+1} R_{t}}+\frac{\theta_{t+1} \mathcal{F}_{t+1}^{c s}}{\Theta_{t+1} R_{t}}
$$

Substituting the guess (A-22) into the budget constraint and using definition (2-24) yields

$$
\begin{aligned}
A_{t}^{c s}(i)+S_{t}^{c s} & +\mathcal{F}_{t}^{c s}+\frac{\theta_{t+1} H_{t+1}^{c s}+\left[\frac{\xi_{t+1}^{w}}{\xi_{t}^{c s}}\right]^{\frac{1}{1-\sigma}}\left(1-\theta_{t+1}\right) H_{t+1}^{w}}{\Theta_{t+1} R_{t}} \\
& =\left[1-\left(1+\tau_{t}^{c}\right) \xi_{t}^{c s}\right]\left[A_{t-1}^{c s}(i) R_{t-1}+H_{t}^{c s}+S_{t}^{c s}+\mathcal{F}_{t}^{c s}\right] .
\end{aligned}
$$

Substituting the guess into the Euler equation results in

$$
\begin{gathered}
\theta_{t+1} \xi_{t}^{c s}\left[A_{t}^{c s}(i) R_{t}+H_{t+1}^{c s}+S_{t+1}^{c s}+\mathcal{F}_{t+1}^{c s}\right]+\left(1-\theta_{t+1}\right) \frac{\Delta_{t+1}^{w}}{\Delta_{t+1}^{c s}}\left[A_{t}^{w}(i, t+1) R_{t}+S_{t+1}^{w}+\mathcal{F}_{t+1}^{w}\right] \\
=\left[R_{t} \Theta t+1 \beta\right]^{\sigma} \xi_{t}^{c s}\left[A_{t-1}^{c s}(i) R_{t-1}+H_{t}^{c s}+S_{t}^{c s}+\mathcal{F}_{t}^{c s}\right] . \quad(\mathrm{A}-27)
\end{gathered}
$$

As before, after guessing that $\xi_{t}^{c s}=\left[\left(\Delta_{t}^{c s}\right)^{\rho}\left(1+\tau_{t}^{c}\right)\right]^{-1}$, the last two conditions imply a first-order non-linear difference equation for the non-restricted young worker's marginal propensity to consume out of total wealth

$$
\frac{1}{\xi_{t}^{c s}}=\left(1+\tau_{t}^{c}\right)+\left[\Theta_{t+1} R_{t}\right]^{\sigma-1}\left(T_{t+1} \beta\right)^{\sigma} \frac{1}{\xi_{t+1}^{c s}} .
$$

Substituting the guess for the value function into the the young worker's objective function leads to

$$
\left(\Delta_{t}^{c s}\right)^{\rho}=1+\left[\Theta_{t+1} R_{t} T_{t+1}\right]^{\sigma-1} \beta^{\sigma}\left(\Delta_{t+1}^{c s}\right)^{\rho} .
$$

Finally, (A-28) and (A-29) imply

$$
\xi_{t}^{c s}=\left[\left(1+\tau_{t}^{c}\right)\left(\Delta_{t}^{c s}\right)^{\rho}\right]^{-1}
$$

and all the guesses are verified. 


\section{B \\ Effects of hand-to-mouth workers on MPC's}

In this appendix, I use a steady state argument to explain the need to include a mass of hand-to-mouth young workers in the model. The MPC's in steady state are given by

$$
\begin{aligned}
\xi^{r} & =\left(1-\gamma R^{\sigma-1} \beta^{\sigma}\right) /\left(1+\tau^{c}\right) . \\
\xi^{w} & =\left[1-(R \Omega)^{\sigma-1} \beta^{\sigma}\right] /\left(1+\tau^{c}\right) . \\
\xi^{c s} & =\left[1-(R \Theta)^{\sigma-1} \beta^{\sigma}\right] /\left(1+\tau^{c}\right) .
\end{aligned}
$$

where variables without a time subscript are in steady state values. I will prove that $\xi^{r}>\xi^{w}>\xi^{c s}$. To begin, I focus on the first part of the inequality.

Assume that $\xi^{r}=\xi^{w}$. Then, definition $(2-21) \Rightarrow \Omega=1 \Rightarrow \xi^{r}>\xi^{w}$, since $\gamma \in[0,1)$. This is a contradiction.

Assume that $\xi^{r}<\xi^{w}$. Again, definition $(2-21) \Rightarrow \Omega>1 \Rightarrow \xi^{r}>\xi^{w}$, which is a contradiction. Those two contradictions prove the first part of the inequality.

Now, I focus on the second part. Assume that $\xi^{w}=\xi^{c s}$. Then, definition $(2-27) \Rightarrow \Theta=1 \Rightarrow \xi^{w}>\xi^{c s}$, since I have already proven that $\Omega<1$. This is a contradiction.

Assume that $\xi^{w}=\xi^{c s}$. Then, definition $(2-27) \Rightarrow \Theta>1 \Rightarrow \xi^{w}>\xi^{c s}$, another contradiction. The second part of the inequality is proved and the proof is finished.

This exercise shows that, at list in steady state, $\xi^{r}>\xi^{w}>\xi^{c s}$. Hence, if every young worker were allowed to smooth consumption, the aggregate MPC of young workers would be lower than the one for mature workers, which is in contrast with recent estimates (Jappelli and Pistaferri, 2014; Fagereng et al., 2019). I solve this problem by assuming that a share $1-\mu$ of young workers is hand-to-mouth.

In steady state, aggregate expenditures on consumption by young workers is given by 


$$
\begin{aligned}
& C^{y}\left(1+\tau^{c}\right)=\left(1+\tau^{c}\right)\left(C^{c s}+C^{h m}\right)= \\
& \quad\left[1-(R \Theta)^{\sigma-1} \beta^{\sigma}\right]\left[A^{c s} R+\hat{H}+\hat{S}+\hat{\mathcal{F}}\right]+(1-\mu) N^{y} W^{y}(1-\tau) .
\end{aligned}
$$

Given definition (2-24), I define the marginal propensity to consume out of current available income for aggregate young workers as

$$
\frac{\partial\left[C^{y}\left(1+\tau^{c}\right)\right]}{\partial\left[N^{y} W^{y}(1-\tau)\right]}=\mu\left[1-(R \Theta)^{\sigma-1} \beta^{\sigma}\right]+(1-\mu)
$$

Expression (B-5) shows that, as $\mu$ gets smaller and the share of handto-mouth young workers increases, the marginal propensity to consume out of current available income for aggregate young workers also increases. In fact, (B-5) shows that young workers MPC for current available income is simply a weighted average of this measure for constrained and unconstrained workers. In the exercise of this paper, I calibrate $\mu$ such that the difference between MPC's of young workers and retirees match empirical studies. 


\section{C \\ Role of credit constrained young workers}

As mentioned in the text, to my knowledge, Carrasco (2019) explicitly accounts for the labor force composition effect when analysing the influence of demographics on interest rates. He built an OLG model with life-cycle wage profile that generates younger workers who are less productive and have higher MPC's. He argues that this outlook is essential for simulating the hump-shaped path of interest rates in the U.S economy since the 1960's. However, Carrasco's (2019) model is very computationally intensive.

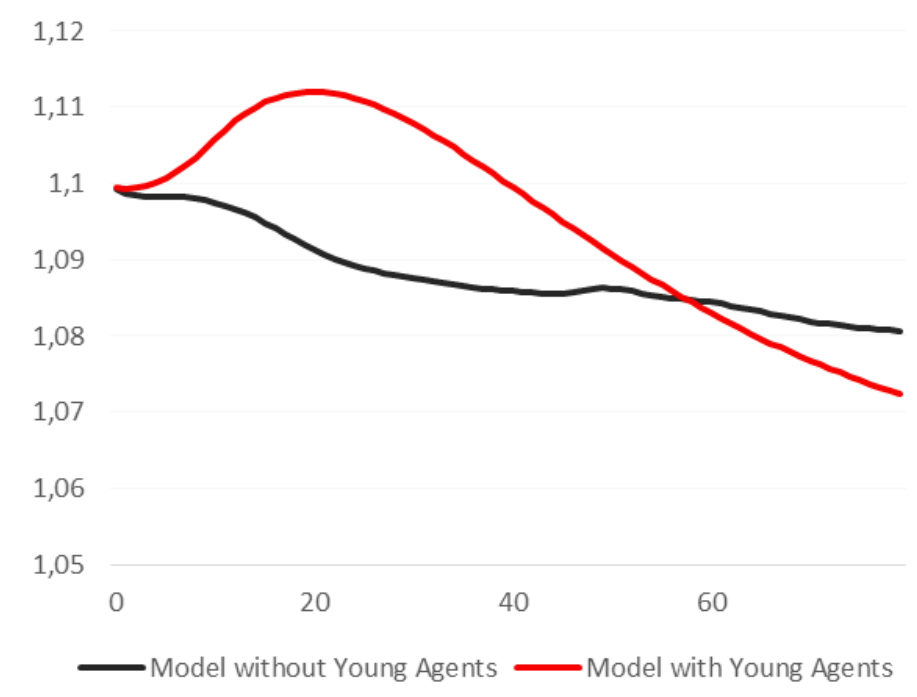

Figure C.1: Comparison between the benchmark model the framework with credit constrained young workers

In this appendix, I argue that extending Gertler's (1999) benchmark model to include a generation of young workers facing credit constraints might be a more efficient to capture the labor force composition effect. I built a simpler version of the model, without any of the particularities of the Brazilian economy (such as compulsory savings, government subsidies and social security). In fact, the model is identical to the original in Gertler (1999), only augmented to include a generation of hand-to-mouth young workers. I calibrate this simpler model in a way that simulations for $\psi^{y, w} \equiv N^{w} / N^{y}$ and $\psi^{w, r} \equiv N^{r} / N^{w}$ match actual data for the U.S. economy since the 1960. I compare the results of this simulation with the ones obtained from 
the benchmark model by Gertler (1999), calibrated to match data on the dependency ratio. Only demographic parameters differ between models.

As shown in Figure C.1, the new framework is capable of reproducing a hump-shape path for interest rates, while the original model is not. Again, this difference is due to the labor force composition effect. Figure C.2 shows that the ratio between mature and young workers is falling in the beginning of the period, which poses an upward force on interest rates. On the other hand, the ratio between retirees and mature workers is increasing because of great increases in life expectancy. In Gertler's (1999) model, there is only an increase in the dependency ratio, because soaring life expectancy more than compensates for population growth effects.
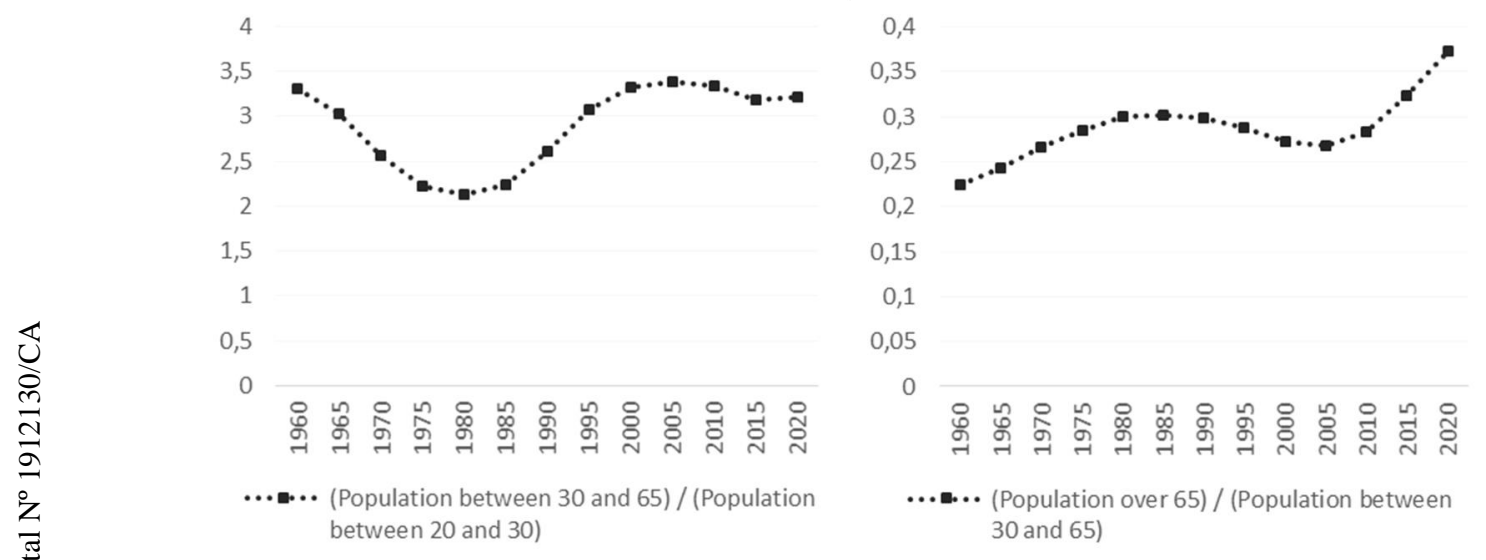

Figure C.2: Population composition in the United States 